\title{
Cutaneous and Mucosal Lichen Planus: A Comprehensive Review of Clinical Subtypes, Risk Factors, Diagnosis, and Prognosis
}

\author{
Farzam Gorouhi, Parastoo Davari, and Nasim Fazel \\ Department of Dermatology, University of California Davis, 3301 C Street, Sacramento, CA 95816, USA \\ Correspondence should be addressed to Nasim Fazel; nasim.fazel@ucdmc.ucdavis.edu
}

Received 31 August 2013; Accepted 20 October 2013; Published 30 January 2014

Academic Editors: G. De Rosa, Y. Hatano, and T. Quan

Copyright (C) 2014 Farzam Gorouhi et al. This is an open access article distributed under the Creative Commons Attribution License, which permits unrestricted use, distribution, and reproduction in any medium, provided the original work is properly cited.

\begin{abstract}
Lichen planus (LP) is a chronic inflammatory disorder that most often affects middle-aged adults. LP can involve the skin or mucous membranes including the oral, vulvovaginal, esophageal, laryngeal, and conjunctival mucosa. It has different variants based on the morphology of the lesions and the site of involvement. The literature suggests that certain presentations of the disease such as esophageal or ophthalmological involvement are underdiagnosed. The burden of the disease is higher in some variants including hypertrophic LP and erosive oral LP, which may have a more chronic pattern. LP can significantly affect the quality of life of patients as well. Drugs or contact allergens can cause lichenoid reactions as the main differential diagnosis of LP. LP is a T-cell mediated immunologic disease but the responsible antigen remains unidentified. In this paper, we review the history, epidemiology, and clinical subtypes of LP. We also review the histopathologic aspects of the disease, differential diagnoses, immunopathogenesis, and the clinical and genetic correlations.
\end{abstract}

\section{Introduction}

Lichen planus (LP) is a chronic inflammatory and immune mediated disease that affects the skin, nails, hair, and mucous membranes. Cutaneous lichen planus (CLP) most commonly involves the flexor surfaces of the extremities and presents as small itchy violaceous Papules in middle-aged adults. "Pruritic, Purple, Polygonal, Planar, Papules, and Plaques" are the traditional 6 "P's" of LP [1]. The lesions are typically bilateral and relatively symmetric. Oral LP (OLP) can be the sole clinical presentation of the disease or accompanied by cutaneous or other mucosal manifestations including the genital area, gastrointestinal tract, and eyes.

\section{Materials and Methods}

In this paper, we review the different aspects of LP, including history, epidemiology, clinical subtypes, histopathologic features, differential diagnoses, immunopathogenesis, clinical and genetic correlations, quality of life, and prognosis of the disease. We searched the literature using terms: "lichen" and "planus."

\section{Results and Discussion}

3.1. History. LP (Greek "Leichen" = tree moss, Latin "planus" = flat, even) [2] was first explained in 1869 by Dr. Wilson as an inflammatory disorder of the stratified squamous epithelia with an unknown etiology. Dr. Wilson probably referred to the condition that was originally described by Herba as "Lichen ruber" [3, 4]. It was originally named "lichen ruber planus" and "lichen psoriasis" [5]. Weyl initially described the characteristic surface markings on LP Papules, known as Wickham striae, in 1885 [6], and Wickham explained it further in 1895 [7]. Darier correlated the presence of Wickham's striae with an increase in thickness of the granular cell layer [8]. In 1937, Guogerot and Burnier described the coexistence of oral, cervical, and stomach LP lesions with no cutaneous involvement as "plurimucosal LP" [9]. In 1982, Pelisse and colleagues reintroduced a similar variant of mucosal LP 
as the vulvovaginal-gingival syndrome with erosive lesions involving the oral and vulvovaginal mucosa [10].

3.2. Epidemiology. The exact prevalence of LP is unknown. Nevertheless, the estimated prevalence of LP is in the range of $0.22 \%$ to $5 \%$ worldwide [11-15]. The epidemiological studies lack clear diagnostic criteria or a uniform methodology. Furthermore, the diverse clinical presentation and the asymptomatic nature of the most common subtype of OLP make the disease an underdiagnosed health issue [16]. McCartan and Healy [17] identified forty-five studies that calculated the prevalence or incidence of LP. They concluded an overall ageadjusted prevalence of $1.27 \%(0.96 \%$ in men and $1.57 \%$ in women) in Sweden $[14,18]$. The incidence of LP was $0.032 \%-$ $0.037 \%$ in a British population [19]. LP typically affects middle-aged adults of both genders. No sexual predilection is evident but some reports indicate a slight predominance in women up to a ratio of $2: 1$ [20]. Interestingly, in the top 3 largest case series of childhood LP, the female to male ratio is reported to be $1: 2$ in a US population [21], 1:1.5 in an Indian cohort [22], and 2:1 in a Canadian study [23]. Such variability may be explained by different inclusion and exclusion criteria within the studies. The relative male predilection in childhood LP is unusual for an autoimmune disease and suggests that other possible unknown mechanisms may be involved in the pathogenesis of LP. Childhood LP is more common in the African American population [23]. Moreover, hypertrophic and actinic variants as well as LP pigmentosus are more prevalent amongst African Americans or darker skinned individuals $[2,24,25]$. Postinflammatory hyperpigmentation is a characteristic outcome of LP lesions that is predominantly more common in the African American population [2]. Asians acquire the follicular form less frequently than the other ethnicities according to a Canadian epidemiological study [26].

\subsection{Clinical Subtypes}

3.3.1. CLP. CLP has different clinical subtypes based on the morphology of the lesions and the site of involvement.

Subtypes Based on Configuration or Morphology of the Lesions. They include papular (classic), hypertrophic, vesiculobullous, actinic, annular, atrophic, linear, follicular, LP pigmentosus and LP pigmentosus-inversus.

The classic CLP lesion is a shiny, red/purple-colored, flattopped papule (Figure 1(a)). Lesions may also have a thin, transparent, and adherent scale. Wickham's striae, which are defined as fine whitish points or lacy lines, may be seen on the surface of well-developed Papules [27].

Hypertrophic LP is characterized by hyperkeratotic thick pruritic red-brown to purple-gray plaques with follicular accentuation [28] that commonly involves the extremities, especially the anterior legs and the interphalangeal joints in a symmetrical distribution (Figure 1(b)) [2]. Welsh et al. described its resemblance to the extrusive forms of igneous rock as a useful sign in distigushing the hypertrophic subtype from other differential diagnoses [28]. Polygonal Papules may be seen surrounding the main lesion.
In the vesiculobullous subtype, blisters develop within the plaques (Figure 1(c)). Lower extremities are the main site of involvement. This pattern of the disease has to be distinguished from LP pemphigoides, a rare coexistence of LP and bullous pemphigoid [29].

Actinic CLP is a rare subtype presenting as nummular patches or plaques with a hypopigmented halo surrounding a hyperpigmented center (Figure $1(\mathrm{~d})$ ). This variant is more prevalent in African Americans, Indians, and Middle-Eastern individuals and affects the sun-exposed areas [30, 31].

Annular CLP is an uncommon form that classically involves the male genitalia (glans penis and penile shaft) and also axilla, groin, and extremities (Figure 1(e)) [32]. Although CLP usually presents with pruritus, the annular form is often asymptomatic especially when arising in the genital area [33].

Atrophic CLP is the clinical endpoint of chronic annular or hypertrophic LP with atrophic lesions (Figure 1(f)) [34]. Diagnosis may be difficult unless classic LP is present elsewhere on the body. The anatomical distribution of lesions may be helpful as it mainly affects the same areas that are involved in the annular or hypertrophic variants. Long-term use of potent or superpotent topical corticosteroids may predispose the patient to developing atrophic lesions.

Linearly oriented lesions of CLP can be caused by the Koebner phenomenon, but this pattern is not considered as the true linear form. The true linear form is more extensive and follows the lines of Blashko [35]. In rare circumstances, if linear LP presents in a dermatomal pattern, it is called zosteriform LP (Figure 1(g)) [36]. This rare variant is found either at the site of healed herpes zoster lesions (Wolf isotopic response) or de novo in normal skin. The exact etiology of the zosteriform subtype remains debatable [37]. The isotopic response can also occur in the annular subtype [38].

LP pigmentosus is usually seen in Indians and darker skinned individuals. Lesions are characteristically bilateral and involve sun-exposed areas [24]. Conversely, LP pigmentosus-inversus was reported in whites and lighterskinned Asians, which typically affects the intertriginous and flexural areas $[39,40]$.

Classic follicular CLP, fibrosing alopecia in a pattern distribution, frontal fibrosing alopecia (FFA), and Graham Little-Piccardi-Lassueur syndrome [41]. The typical form of LPP is characterized by pinpoint hyperkeratotic Papules often found on the scalp. It frequently affects the vertex but can also involve other parts of the scalp [42]. LPP has a sexual predilection for females and can involve nail and mucosa $[43,44]$. LPP can also be induced by hair transplantation or face-lift surgery. The possible triggering factors include the Koebner phenomenon, perisurgery antigen release, or the postoperative immune-inflammatory response $[45,46]$. "Fibrosing alopecia in a pattern distribution" is another suggested subtype that has a centroparietal pattern. It lacks the multifocal scarring of classic LPP and can be discerned accordingly [47]. FFA is more commonly seen in postmenopausal women. The pattern of alopecia is analogous to male pattern androgenetic alopecia with frontal dominance and additional features such as scarring and a lichenoid pattern on histopathology [48]. Graham Little-PiccardiLassueur syndrome is a rare variant of LPP characterized 


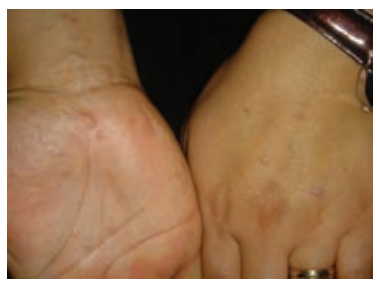

(a)

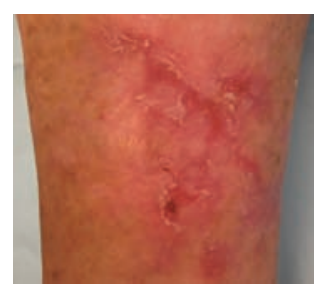

(b)

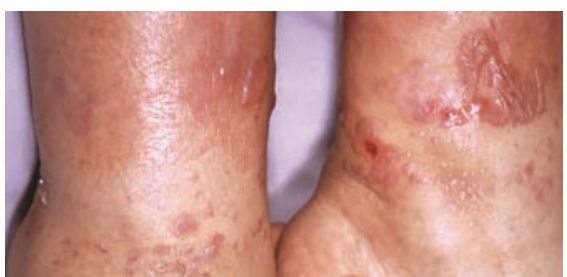

(c)

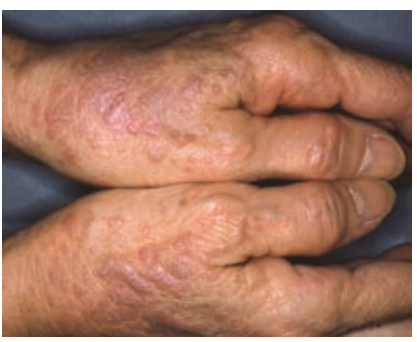

(d)

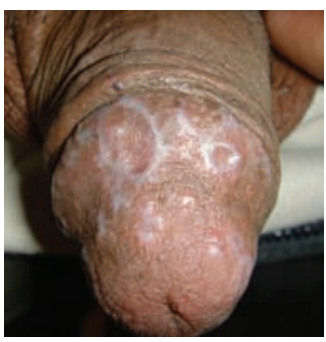

(e)

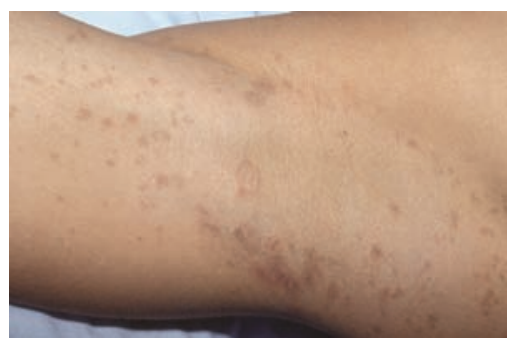

(f)

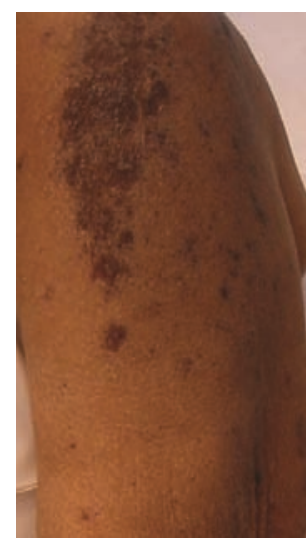

(g)

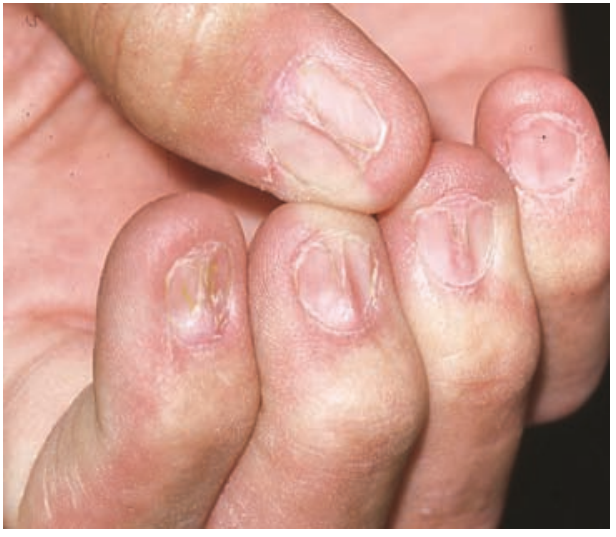

(h)

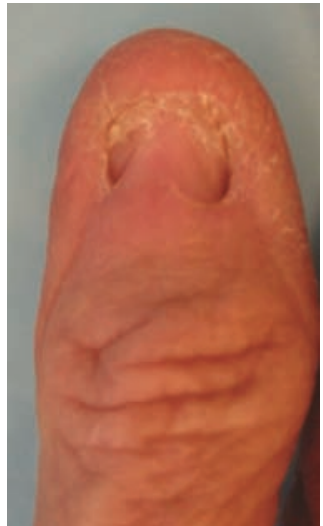

(i)

Figure 1: (a) Classic CLP: violaceous Papules on the dorsal hand and volar wrist (courtesy of Dr. Omid Zargari); (b) hypertrophic CLP: centrally eroded hyperkeratotic plaques involving the lower leg; (c) vesiculobullous CLP: vesicles and bullae on right and left ankles and lower legs (courtesy of Dr. Peter Lynch); (d) actinic CLP: hyperpigmented Papules and plaques on the dorsal hands (courtesy of Dr. Peter Lynch); (e) annular CLP: reticulated white striae involving the glans penis (courtesy of Dr. Omid Zargari); (f) atrophic CLP: hyperpigmented macules and patches on the arm (courtesy of Dr. Peter Lynch); (g) zosteriform CLP: linearly oriented confluent violaceous Papules on the arm; (h) nail CLP: longitudinal ridging of the fingernails (courtesy of Dr. Peter Lynch); (i) nail CLP: dorsal pterygium of the thumbnail; (a), (b), (e), (g), and (i) are reprinted with permission from [50]. CLP, cutaneous lichen planus.

by the triad of follicular-based spinous Papules on the body, scalp, or both, patchy cicatricial alopecia of the scalp, and noncicatricial alopecia of the axilla and pubic region. It is preferentially more common in females [49].

Lichen Planus Subtypes Based on the Site of Involvement. Palmoplantar LP is a rare subtype. The erythematous scaly form is the most common clinical presentation. The lesions are multiple (more than 10 lesions), bilateral, and often symmetrical with prominent associated pruritus. The most common sites of involvement include the malleoli and also the internal plantar arch [51]. Fingertips are often spared. The second most common clinical form presents as hyperkeratotic plaques [51]. Palmoplantar LP can less frequently present as vesiculobullous lesions [52].

The scalp is the main site of follicular CLP or LPP as described above.

LP causes nail lesions in 1-10\% of adult cases (Figures 1(h) and 1(i)). Nail LP is more commonly seen in children [53]. One study reported a prevalence of $19 \%$ in a cohort of 100 childhood LP cases from India [22]. Tosti and coworkers noted that nail LP may be underdiagnosed 


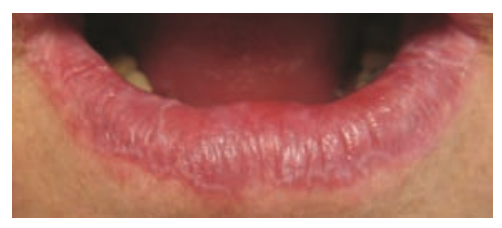

(a)

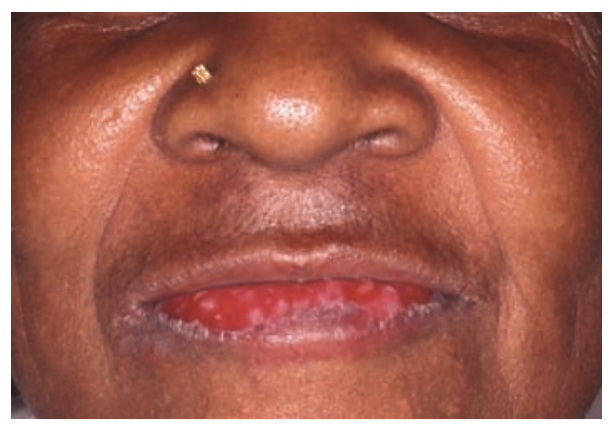

(c)

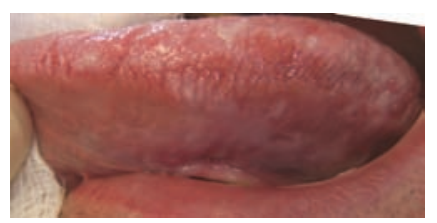

(b)

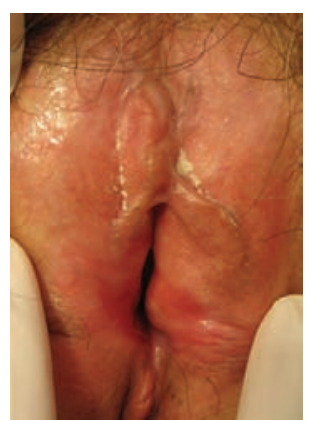

(d)

Figure 2: (a) Reticular OLP: reticulated white striae of the lower lip proper; (b) plaque-type OLP: confluent white reticulated plaques of the lateral tongue; (c) erosive OLP: superficial erosions and white striae of the lower lip proper (courtesy of Dr. Peter Lynch); (d) vulvar LP: superficial erosions at the vulvar introitus with fusion of the labia minora and vaginal stenosis; Figures 1(a) and 1(b) are reprinted with permission from [50]. OLP, oral lichen planus.

in children because of the fact that isolated nail lesions are more common in this age group [53]. Likewise, Kanwar and De suggested that the general hesitation of dermatologists to perform nail biopsies on children may be another reason for underdiagnosis of the disease in this age group [22]. Fingernails are more commonly involved than toenails [54]. Although it can affect both the nail matrix and the nail bed, the diagnosis of classic nail LP should be based on destruction of the nail bed with longitudinal fissuring and ridging of the nail plate, brittleness (onychorrhexis) and spontaneous separation of the nail plate (onycholysis) $[53,55,56]$. Nail involvement may irreversibly deform or destroy the nails. Dorsal pterygium is one of the characteristic findings and may be present in the classic form [53, 57]. Twenty-nail dystrophy is characterized by nail coarseness affecting all fingernails and toenails because of excessive longitudinal ridging (trachyonychia). This clinical presentation is observed in LP as well as other diseases that involve the nail matrix such as alopecia areata, psoriasis, eczema, and pemphigus vulgaris [53]. In rare circumstances, localized distal subungual hyperkeratosis with multinucleated cells can arise (onychopapilloma) [58]. Additionally, melanonychia can be induced with resolution of the lesions [59]. The lunula may be irregularly red in a focal or disseminated pattern due to the associated inflammation. In the toenails, remarkable thickening may be noted and can be mistaken with yellow nail syndrome. Furthermore, erosive nail LP may rarely occur with painful erosions and consequent scarring [54]. Another rare variant, idiopathic atrophy of the nails, can cause rapid diffuse nail atrophy and pterygium of the nails and can ultimately lead to permanent anonychia [54].

3.3.2. Mucosal LP. Mucosal LP more commonly involves the oral mucosa but can also affect the vulvovaginal area. LP can rarely manifest in the esophagus, larynx, and conjunctiva [60].

OLP. OLP has several clinical subtypes including reticular, erosive, atrophic, papular, plaque-like, and bullous subtypes. Figures 2(a)-2(c) illustrate different subtypes of OLP. The buccal mucosa is typically involved in $80-90 \%$ of OLP cases. The Koebner phenomenon is not only present in CLP but can also occur in the setting of OLP. Eisen [20] suggested that the mechanical trauma of dental procedures, cigarette smoking, mucosal trauma from sharp cusps, and oral habits such as lip chewing are Koebnerogenic factors that can exacerbate OLP. Reticular OLP, the most common subtype, is usually asymptomatic. Hence, it is often diagnosed during a routine oral examination. Reticular OLP is characterized by white lacy streaks surrounded by well-defined erythematous borders. This pattern is less evident on the dorsum of the tongue [61]. In some patients, reticular OLP may eventually progress to the more severe subtypes such as the erosive form. Papular OLP is characterized by small white pinpoint Papules that can be easily missed as they are small and asymptomatic. It is referred to as the initial and transient phase of OLP [62]. That is why it is a rare diagnosis $[63,64]$. In plaque-like OLP, large, homogenous white patches are characteristic. Plaquelike OLP and leukoplakia have similar clinical presentations and therefore leukoplakia must always be ruled out [64]. This variant is more prevalent in tobacco smokers [62]. The existence of plaque-like lesions is an indicator of a poor prognosis and a lesser likelihood of remission [62]. Erosive OLP, the most advanced subtype, can clinically present as atrophic or erythematous ulcerations and erosions of the mucosa and faint radiating white striae. The associated ulcers are sometimes covered with a pseudomembrane. Typically, it has a multifocal pattern of distribution. It is clinically 
important because the lesions can be quite painful and therefore it may negatively affect the patient's quality of life. The symptoms may range from discomfort to severe, painful episodes. Involvement of the dorsum of the tongue might cause dysgeusia [16]. The atrophic subtype is common presentation that has similarities to the erosive subtype with more prominent atrophic lesions on a background of erythema and radiating white striae at the margins. Thus, some experts combine the two entities and name it atrophicerosive lichen planus. This subtype is more common in older OLP patients [62]. Atrophic OLP primarily affects the attached gingiva [64]. The buccal mucosa can also be involved, particularly in the posteroinferior areas adjacent to the second and third molar teeth [65]. In rare instances, OLP may present with bullous lesions. Lourenço and colleagues suggested a rare form of OLP as "Lichen planus sialadenitis," a mucosal analog of LPP due to lymphocyte infiltration in the salivary gland ducts [66].

Vulvovaginal LP. Vulvar LP can affect peri- or postmenopausal women with rare occurrence in children [67]. Vulvovaginal LP has a similar pattern to OLP. Figure 2(d) illustrates vulvar LP. It has three major subtypes: erosive, papulosquamous, and hypertrophic [68]. Erosive vulvar LP is the most frequent subtype, involving the mucous membranes exclusively [69]. The most significant sequelae of chronic erosive vulvar LP are scarring, which can result in resorption of the labia minora (agglutination) and clitoral hood, with subsequent clitoral burying (synechiae, 68\%), stenosis of the introitus (59\%), and potentially total obliteration of the vagina. The associated scarring and adhesions affecting the vagina may interfere with sexual intercourse [70,71]. It is essential to consider the patient's psychological status and quality of life, which can be deeply affected by the disease. Sexual abstinence or dyspareunia was present in 46 out of 58 patients diagnosed with genital erosive LP referred to a specialized center in Norway over a 7-year period [72]. It is also beneficial to document the extent and location of the lesions in the vulva and examine other mucocutaneous sites of LP at each visit [73]. In addition to dyspareunia, vulvar LP can lead to symptoms of intense pruritus with chronic vaginal discharge, burning, and postcoital bleeding [72, 74]. The presentation of papulosquamous and hypertrophic vulvar LP is similar to their corresponding OLP subtypes. Furthermore, $43 \%-100 \%[60,70,73]$ of vulvar cases may have concomitant oral involvement, whereas about $25 \%$ of OLP patients may have vulvar involvement [20]. The coexistence of oral and genital lesions is known as vulvovaginal-gingival syndrome [75]. Skin lesions are as frequent as $17 \%-22 \%$ in this syndrome $[60,73]$.

Esophageal LP. LP of the esophagus is a rare presentation of the disease. It is an underdiagnosed and underreported entity with a sexual predilection in women [76]. In the majority of cases, esophageal LP may be accompanied by other mucosal lesions or less commonly concomitant with cutaneous manifestations. It may also present as an isolated disease in its initial presentation (20\%). Ultimately, extraesophageal lesions can be found in almost all patients with esophageal LP [76]. The proximal esophagus is affected in $90 \%$ of cases with or without distal involvement. In may cases, there is a significant delay between the onset of symptoms and detection of esophageal involvement. Thyroid dysfunction is the most common associated disorder [76]. In a casecontrol study, superficial gastritis was significantly more common in LP patients than healthy controls [77]. Therefore, it is important to consider upper GI endoscopy particularly in LP patients with complaints of dysphagia, odynophagia, weight loss, or other esophageal symptoms and those with involvement of other mucosal surfaces [78].

Ocular LP. LP may be accompanied by significant ophthalmologic problems including a decrease in tear production [79]. More than one third of LP patients have blepharitis [79]. Şanli and coworkers also noted a lower number of goblet cells in the conjunctival epithelium of LP patients, when compared to controls [79]. Ocular involvement may also cause mild to moderate xerophthalmia and occasionally cicatricial conjunctivitis $[79,80]$. Conjunctival involvement can start with white streaks involving the palpebral conjunctiva [80]. In a case series of 9 LP patients with ophthalmological signs, 7 cases had vulvovaginal-gingival syndrome and all patients developed subepithelial fibrosis and lacrimal duct stenosis [81]. Webber et al. recommended ophthalmologic evaluation and examination of the lacrimal duct puncta in erosive LP patients [81]. Other ophthalmologic signs include eyelid lesions [82, 83], keratouveitis [80], keratoconjunctivitis sicca [80], punctate epithelial erosions [80, 84], corneal ulceration/scarring [84], and dysplastic conjunctival lesions resembling ocular surface squamous neoplasia [85]. LP was also reported as chronic keratoconjunctivitis with diffuse conjunctival hyperemia, subconjunctival fibrosis, and forniceal symblephara with foreshortening of the lower fornix in the isolated ocular form [86]. This form of the disease can be a diagnostic challenge [87]. Biopsy for histopathologic examination and immunofluorescence studies is the only way to differentiate ocular LP from other causes of irreversible scarring keratoconjunctivitis [86]. The presence of subepithelial fibrinogen is not necessarily inclusive of any particular eye disease on immunofluorescence analysis, but a fragmented and shaggy subepithelial fibrinogen layer in the conjunctiva is indicative of LP $[88,89]$. It is essential to diagnose and treat such disease quickly and efficiently to avoid the dire consequences of blindness [90].

Laryngeal LP. Involvement of the larynx is extremely rare. In fact, few patients with laryngeal LP have been reported [91-93]. The first case was a 57-year-old Caucasian man with isolated laryngeal LP and complaints of hoarseness [91]. The second case was an 18-year-old Pakistani man with mucosal LP in the mouth, conjunctivae, and larynx [92]. Kunelskaya Ya. and Arievich reported the largest case series of laryngeal involvement in 8 mucosal LP patients. They noted involvement of epiglottis and aryepiglottic folds but no involvement of vocal cords. The lesions were larger in the epiglottis region than other parts of the larynx [93].

Table 1 addresses the most common sites of involvement for LP subtypes. 
TABLE 1: The most common sites of involvement in LP based on subtypes.

\begin{tabular}{|c|c|}
\hline Subtypes & Most common sites of involvement \\
\hline \multicolumn{2}{|r|}{ CLP } \\
\hline Actinic & Sun-exposed areas such as face, V-chest, hands \\
\hline Annular & Male genitalia (penis, scrotum), axilla, groin folds \\
\hline Atrophic & All parts of body especially lower extremetities \\
\hline Erosive & Soles of feet \\
\hline Follicular & Scalp \\
\hline Guttate & Trunk \\
\hline Hypertrophic & Anterior leg, ankles, and interphalangeal joints \\
\hline Linear & Leg-excoriated area \\
\hline Papular & Flexor surfaces (the main initial presentation) \\
\hline Bullous & Feet \\
\hline Pigmentosus & Sun exposed areas such as face, V-chest, hands \\
\hline Pigmentosus-inversus & Intertriginous and flexural areas \\
\hline Nail involvement & Fingernails and toenails \\
\hline Palmoplantar involvement & $\begin{array}{l}\text { (1) Malleoli } \\
\text { (2) Soles (internal plantar arch) }\end{array}$ \\
\hline Lichen planopilaris & $\begin{array}{l}\text { (1) Vertex of scalp (classic type) } \\
\text { (2) Frontal of scalp (FFA type) }\end{array}$ \\
\hline \multicolumn{2}{|r|}{ Mucosal LP } \\
\hline \multicolumn{2}{|l|}{ Oral } \\
\hline Reticular & $\begin{array}{l}\text { (1) Buccal mucosa and mucobuccal folds } \\
\text { (2) Lateral and dorsal tongue } \\
\text { (3) Gingiva and lips }\end{array}$ \\
\hline Atrophic & Attached gingiva \\
\hline Hypertrophic & Buccal mucosa \\
\hline Erosive & $\begin{array}{l}\text { (1) Lateral and ventral portions of tongue } \\
\text { (2) Buccal mucosa }\end{array}$ \\
\hline Bullous & Posterior and inferior areas of buccal mucosa \\
\hline Plaque-like & Dorsum of the tongue and buccal mucosa \\
\hline \multicolumn{2}{|l|}{ Vulvovaginal } \\
\hline All subtypes & Vaginal introitus, clitoris, clitoral hood, labia minora, and majora, vagina \\
\hline Esophageal & $\begin{array}{l}\text { (1) Proximal esophagus } \\
\text { (2) Proximal and distal esophagus } \\
\text { (3) Distal esophagus, strong possibility of concomitant mucosal involvement (80\%) }\end{array}$ \\
\hline
\end{tabular}

FFA: frontal fibrosing alopecia, CLP: cutaneous lichen planus, FFA: frontal fibrosing alopecia, LP: lichen planus.

3.4. Diagnosis. The diagnosis of LP is based on the clinical presentation and should be confirmed by biopsy, if suspected. Histopathology is often conclusive, but in vesiculobullous CLP or erosive OLP, direct immunofluorescence (DIF) studies can be an integral step in differentiating between LP and other diseases [16]. DIF typically demonstrates globular IgM deposition at the dermal-epidermal junction in LP [94]. Although the existence of fibrin deposition at the mucosal submucosal interface and within vessels and the presence of colloid bodies is highly sensitive for a diagnosis of LP, it lacks specificity [95]. Indirect immunofluorescence and enzymelinked immunosorbent assays can also be helpful in reaching a diagnosis [16].

3.4.1. Histopathology. LP is characterized by lichenoid interface dermatitis. The classic histopathological features include a dense, continuous, and band-like lymphohistiocytic infiltrate at the dermal-epidermal junction and in the upper dermis. Characteristically, the infiltrate disguises the dermalepidermal junction and makes it difficult to recognize the basal layer at the early stages of the disease [96]. Epidermal changes in LP lesions include irregular epidermal hyperplasia with a jagged "sawtooth" appearance, compact hyperkeratosis or orthokeratosis, foci of wedge-shaped hypergranulosis, basilar vacuolar degeneration, slight spongiosis in the spinous layer, and squamatization. The dermal papillae between the elongated rete ridges are frequently dome shaped [97]. Necrotic keratinocytes can be observed in the basal layer of the epidermis and at the dermal-epidermal junction. Eosinophilic remnants of anucleate apoptotic basal cells may also be found in the dermis and are referred to as "colloid or civatte bodies" [1]. Whickham striae are usually seen in 
the areas of hypergranulosis [1]. Vacuolar degeneration at the basal layer may be noted leading to focal subepidermal clefts (Max Joseph spaces) [98]. Squamatization occurs as a result of maturation and flattening of cells in the basal layer [1]. It happens in areas of marked hypergranulosis with prominence of the sawtooth pattern of rete ridges [94]. Wedge-shaped hypergranulosis can occur in the eccrine ducts (acrosyringia) or hair follicles (acrotrichia) [99]. In the hypertrophic subtype, the associated hyperkeratosis, parakeratosis, hypergranulosis, papillomatosis, acanthosis, and hyperplasia markedly increased with thicker collagen bundles forming in the dermis $[94,99]$. Moreover, the rete ridges are more elongated and rounded as opposed to the typical sawtooth pattern [94]. In atrophic LP, loss of the rete ridges and dermal fibrosis is prominent [99]. In vesiculobullous LP, the disease progression is quicker. Hence, some of the distinctive features such as hyperkeratosis, hypergranulosis, or dense lymphocytic dermal-epidermal infiltrate may not be present [99]. LP lesion may resolve with residual hyperpigmentation caused by a persistent increase in the number of melanophages in the papillary dermis $[96,100]$.

In classic LPP, the bandlike lymphocytic infiltrate is initially contained in the peribulge area including the infundibulum and isthmus with sparing of the lower segment of the hair follicle. The same follicular segments may exhibit orthokeratosis, hypergranulosis, and follicular plugging [96]. The interfollicular epidermis is rarely affected [43]. LPP leads to permanent hair loss due to the involvement of hair follicle stem cells in the bulge. Fibrotic tissue can progressively replace the hair follicles [101].

In mucosal lesions, the epithelial changes are less specific. The rete ridges do not exhibit the characteristic pronounced sawtooth pattern because normal oral mucosa exhibits parakeratosis with no granular layer [102]. Hence, OLP lesions rarely exhibit orthokeratosis. OLP lesions are likely to be more atrophic than acanthotic as compared to CLP [96]. Contrary to CLP and OLP, histolopathological findings in genital erosive LP are less specific and often inconclusive $[70,73]$.

3.4.2. Differential Diagnosis. The differential diagnosis of LP is fairly broad and summarized in Table 2 . An important entity in the differential diagnosis of LP is lichenoid drug reactions, which can virtually be indistinguishable from cutaneous LP both clinically and histopathologically. Typically, lesions have a photodistribution in the absence of oral mucosal involvement. The most commonly implicated drugs are summarized in Table 3. Lichenoid drug reactions characteristically exhibit parakeratosis, a dermal eosinophilic infiltrate, and a perivascular lymphocytic infiltrate affecting the reticular dermis. Epidermal changes are less common in lichenoid drug eruptions when compared to classic LP [94]. However, a higher concentration of necrotic keratinocyte and eosinophils in the infiltrate can be helpful in distinguishing lichenoid drug reaction from cutaneous LP [103]. A lengthy interval between the commencement of drug therapy and the onset of lesions does not exclude a diagnosis of lichenoid drug reaction [16]. Resolution of the lesions often occurs within weeks to months after discontinuation of the offending drug [104].

Lichenoid contact reaction is an important consideration in the differential diagnosis of LP. Patch testing and challenge testing can be utilized to properly identify the causal allergen. As suggested in other patch test studies, one should interpret positive patch test results to any particular allergen in the context of its clinical relevance. In a retrospective cohort study of patients with contact stomatitis or contact mucositis, 46/198 patients were diagnosed with OLP and had undergone patch testing. Fourteen out of forty-six patients (40\%) had identifiable contact hypersensitivity [105]. The main triggering contact allergens involved in lichenoid contact reactions are shown in Table 4. Metals can induce or aggravate lichenoid contact reactions including silver-mercury amalgam fillings and other metals containing dental restorative materials [106]. In a prospective study from Basque, such lichenoid reactions were limited to old and corroded dental fillings [107]. Even patients with negative patch test results are likely to benefit from removing corroded restorations simply by omitting the mucosal irritation induced by them as a result of Koebner's phenomenon [108]. Food flavorings can also induce lichenoid reactions including cinnamon, cinnamonic aldehyde, and spearmint oil present in foods and dentifrices $[109,110]$. A rare lichenoid form of mycosis fungoides (MF) can mimic CLP lesions. Lichenoid MF has more eosinophils, mast cells, lymphocytic nuclear atypia, and more basilar epidermotropism as compared to CLP [111]. Lichenoid MF is extremely pruritic and has a poor prognosis. Therefore, prompt diagnosis and management is crucial [111].

Resolving ashy dermatosis can be considered in the differential diagnosis of hyperpigmented CLP lesions. Both have similar histopathologic features. However, they can be differentiated from each other by their color (blue-gray/ashybrown for ashy versus black-brown/violet-blue for LP), the absence of erythematous borders in LP pigmentosus, and the absence of itching in ashy dermatosis [112].

Lichen nitidus may be difficult to clinically distinguish from generalized LP with a dense lymphohistiocytic infiltrate on histopathology [113].

Differentiating between pseudopelade of Brocq and scarring classic LPP can be challenging as they both have multifocal involvement of the vertex scalp although LPP presents more frequently with perifollicular erythema and follicular keratotic plugs than pseudopelade of Brocq $[43,114]$. There is an ongoing debate as to whether pseudopelade of Brocq is a subtype of LPP [47].

Lichen striatus has a clinical presentation similar to linear LP. It presents as unilateral linear erythematous itchy Papules in young adults and children. It is histopathologically differentiated from linear LP by exhibiting more prominent parakeratosis and spongiosis [115].

Distinguishing between the cicatricial alopecia induced by LPP and discoid lupus erythematosus (DLE) can be challenging. Unlike DLE, LPP often spares the interfollicular epidermis [42]. Dermatoscopic examination can also be helpful. Perifollicular scale and branching capillaries are distinguishing dermatoscopic signs for LPP and DLE, respectively [116]. 
TABLE 2: LP differential diagnosis.

\section{CLP}

\begin{tabular}{|c|c|}
\hline \multicolumn{2}{|r|}{ CLP } \\
\hline Papular classic & $\begin{array}{l}\text { Psoriasis, chronic cutaneous lupus erythematosus, lichen simplex chronicus, graft-versus-host } \\
\text { disease, secondary syphilis, pityriasis rosea, lichenoid mycosis fungoides }\end{array}$ \\
\hline Annular & Granuloma annulare, tinea \\
\hline Linear & $\begin{array}{l}\text { Lichen striatus, inflammatory linear verrucous epidermal nevus (ILVEN), linear psoriasis, } \\
\text { linear Darier-White disease, nevus unius lateris }\end{array}$ \\
\hline Hypertrophic & $\begin{array}{l}\text { Psoriasis, prurigo nodularis, lichenoid cutaneous amyloidosis, Kaposi sarcoma, lichen simplex } \\
\text { chronicus, stasis dermatitis }\end{array}$ \\
\hline Vesiculobullous & Lichen planus pemphigoides, bullous pemphigoid, pemphigus vulgaris \\
\hline LP pigmentosus & Ashy dermatosis \\
\hline Atrophic & Lichen sclerosus et atrophicus, lupus, ashy dermatosis \\
\hline Generalized & Lichen nitidus, drug eruptions, guttate psoriasis, viral exanthems \\
\hline \multicolumn{2}{|r|}{ LP of skin appendages } \\
\hline Follicular CLP (LPP) & Lichen spinulosus \\
\hline LPP induced cicatricial alopecia & $\begin{array}{l}\text { Pseudopelade of Brocq, follicular degeneration syndrome, androgenetic alopecia, chronic } \\
\text { cutaneous lupus erythematosus }\end{array}$ \\
\hline Nail CLP & $\begin{array}{l}\text { Brittle nails, lichen striatus, graft versus host disease, systemic amyloidosis, trauma, } \\
\text { dyskeratosis congenital }\end{array}$ \\
\hline Idiopathic atrophy of nails & Hereditary anonychia, impaired peripheral circulation, epidermolysis bullosa \\
\hline Trachyonychia & Alopecia areata and psoriasis \\
\hline Toenail LP & Yellow nail syndrome \\
\hline Erosive nail LP & Blistering disease nail involvement \\
\hline \multicolumn{2}{|r|}{ Mucosal LP } \\
\hline OLP & $\begin{array}{l}\text { Leukoplakia, candidiasis, erythema multiforme, pemphigus vulgaris, bullous pemphigoid, } \\
\text { lichen sclerosus, secondary syphilis, bite trauma, lichen sclerosus et atrophicus, lupus, ashy } \\
\text { dermatosis }\end{array}$ \\
\hline Vulvar LP & Lichen sclerosis, valvovaginal blistering diseases \\
\hline
\end{tabular}

CLP: cutaneous lichen planus, LP: lichen planus, LPP: lichen planopilaris, OLP: oral lichen planus.

Granuloma annulare does not present with scale or Wickham striae, but it may resemble annular LP [34].

Vesiculobullous CLP and LP pemphigoides are difficult to differentiate. LP pemphigoides can be clinically distinguished by a more generalized distribution, more extensive blistering, and a more chronic course [117].

Blistering diseases and lupus erythematous are on the list of differential diagnoses of OLP. The differential diagnosis of OLP from other diseases is particularly difficult in the nonreticulated forms often necessitating biopsy and DIF studies [16]. Erosive/ulcerative OLP should be distinguished from mucous membrane pemphigoid. The presence of whitish hyperkeratotic striations and skin involvement are important differentiating features [118]. The DIF pattern of a pemphigoid lesion will most often include linear IgG and C3 and rarely, IgM at the basement membrane level. Table 5 presents the DIF patterns of the differential diagnoses of LP.

Vulvar mucosal LP can be misdiagnosed as lichen sclerosis or vulvovaginal blistering diseases. The classic Wickham striae and histopathologic examination can be helpful in making the distinction.

3.5. Immunopathogenesis. LP is a T-cell-mediated autoimmune disease. Inflammatory cells involved in this process consist of $\mathrm{T}$ helper and $\mathrm{T}$ cytotoxic lymphocytes, natural killer (NK) cells, and dendritic cells. T-cell activation is central to the pathogenesis of LP. Cytotoxic T-cell infiltration into the epithelium results in apoptotic basal keratinocytes. Theoretically, it may be induced by CXCR3 and CCR5 mediated signaling pathways initiated by both T-cells and keratinocytes [119]. In the early stages, T-cells predominantly home in the deeper layers of the epidermis and at the dermalepidermal junction [119]. CCR5 related chemokines as well as CXCR3-targeting chemokines are significantly overexpressed in LP lesions in concert with the increased trafficking of mononuclear cells to the interface region [120, 121]. This correlation or coincidence suggests that both keratinocyte induced- and self-recruiting mechanisms are involved in Tcell migration within LP lesions. Furthermore, Langerhans cell recruitment is induced by CCR6 related chemokines [119]. Activated T-cells stimulate the T helper type 1 (Th1) response, thus resulting in keratinocyte removal by immune cells [120].

The TH1 dominance in LP patients is partly regulated through toll-like receptor (TLR) 2 upregulation [120]. TLR is mainly involved in innate immunity but can also trigger adaptive immunity. TLR2 activation is known to induce TH1 activation. However, there is a contrasting result from a study suggesting downregulation of TLR2 and upregulation of TLR4 in OLP patients [122]. Moreover, in OLP patients, 
TABLE 3: Drugs responsible for lichenoid reaction.

\section{Anticholinergics}

(i) Solifenacin

Anticonvulsants

(i) Carbamazepine

(ii) Oxcarbazepine

(iii) Phenytoin

(iv) Valproate sodium

Antidiabetics

(i) Chlorpropamide

(ii) Glyburide

(iii) Glipizide

(iv) Insulin

(v) Tolazamide

(vi) Tolbutamide

Antidiarrheals

(i) Bismuth

Antigout

(i) Allopurinol

Antihistamine drugs

(i) Cinnarizine

(ii) Iodides

Anti-inflammatory

drugs

(i) Aspirin

(ii) Diflunisal

(iii) Ibuprofen

(iv) Indomethacin

(v) Leflunomide

(vi) Mesalamine

(vii) Naproxen

(viii) Rofecoxib

(ix) Sulindac

(x) Sulfasalazine

(xi) Tolbutamide

Antimalarials

(i) Chloroquine

(ii) Hydroxychloroquine

(iii) Pyrimethamine

(iv) Quinidine

(v) Quinine

Antimicrobials

Antibiotics

(i) Para-aminosalicylic acid

(ii) Sulphamethoxazole

(iii) Tetracycline

Antimycobacterials

(i) Aminosalicylate

sodium

(ii) Dapsone

(iii) Ethambutol

(iv) Isoniazid

(v) Rifampin

(vi) Streptomycin

Antifungals

(i) Amphotericin B

(ii) Griseofulvin

(iii) Ketoconazole

Antihelminthic

(i) Levamisole
TABle 3: Continued.

\begin{tabular}{ll}
\hline & Other medications \\
& (i) Amiphenazole \\
& (ii) Clopidogrel \\
& (iii) Penacillamine \\
& (iv) Palifermin \\
Antiparkinsoniandrugs & (v) Mercapto-propionylglycine \\
(i) Trihexyphenidyl & (vi) Misoprostol \\
Antiretrovirals & (vii) Nandrolene \\
(i) Zidovudine & (viii) furyl-propionate \\
Chemotherapy drugs & (Demelon) \\
(i) Hydroxyurea & (ix) Norflex \\
& (x) Omeprazole \\
& (xi) Pyrithioxin \\
& (xii) Sildenafil \\
& (xiii) Tiopronin \\
\end{tabular}

Modified from Schlosser [16].
Cardiovascular drugs

(i) Atenolol

(ii) Captopril

(iii) Doxazosin

(iv) Diazoxide

(v) Enalapril

(vi) Labetalol

(vii) Metoprolol

(viii) Methyldopa

(ix) Nebivolol

(x) Nicorandil

(xi) Nifedipine

(xii) Prazosin

(xiii) Procainamide

(xiv) Propranolol

(xv) Quinidine

(xvi) Terazosin

Diuretics

(i) Chlorothiazide

(ii) Furosemide

(iii) Hydrochlorothiazide

(iv) Spironolactone

Immunomodulatory and

biological therapies

(i) Adalimumab

(ii) Dactinomycin

(iii) Etanercept

(iv) Gold salts

(v) Imatinib mesylate

(vi) Infliximab

(vii) Interferon- $\alpha$

(viii) Penicillamine

(ix) Tacrolimus

Lipid lowering drugs

(i) Gemfibrozil

(ii) Orlistat

(iii) Pravastatin

(iv) Simvastatin

Metals

(i) Arsenic

Psychiatricdrugs

(i) Antipsychotics

(Chlorpromazine,

Levomepromazine,

Methopromazine, Thioridazine)

(ii) Benzodiazepines

(Lorazepam)

(iii) Imiquimod

(iv) Lithium

(v) Selective serotonin reuptake inhibitor (Escitalopram)

(vi) Tricyclic antidepressants

(Amitriptyline, Imipramine)

Retinoids

(i) Isotretinoin
TABLE 4: Possible contact allergens to induce lichenoid contact reactions.

\begin{tabular}{|c|c|}
\hline $\begin{array}{l}\text { Dental restoration/ } \\
\text { crowning materials }\end{array}$ & $\begin{array}{l}\text { Beryllium, cobalt, copper, chromium, gold, } \\
\text { indium, mercury, nickel, palladium, silver, } \\
\text { tin, zinc, composite resins, ceramics } \\
\text { (porcelain), ethylene glycol dimethacrylate, } \\
\text { titanium }\end{array}$ \\
\hline Flavorings & $\begin{array}{l}\text { Menthol oil, peppermint, cinnamon, } \\
\text { spearmint, balsam of Peru, vanillin, jasmine } \\
\text { absolute, lemon oil, eugenol }\end{array}$ \\
\hline
\end{tabular}

Modified from Schlosser [16].

TLR4 and TLR9 are upregulated in the superficial and basal layers, respectively [123].

NK cells can migrate to LP lesions more frequently than to healthy skin [124]. They may contribute to the pathogenesis of LP due to their cytotoxic activity and their ability to secrete proinflammatory cytokines [124].

One of the main pathogenetic mechanisms of LP is increased apoptosis of keratinocytes and decreased apoptosis of T-cells [125]. Activated cytotoxic T-cells can upregulate the Fas ligand and induce keratinocyte apoptosis in the suprabasal cell layer by binding to Fas on the surface of keratinocytes [126]. NK cells and cytotoxic T-cells may also induce apoptosis via the granzyme $\mathrm{B} /$ perforin pathway. This autodestructive immunologic mechanism is more abundant in OLP than CLP [127]. The altered immune response results in apoptosis of basilar keratinocytes and ultimately leads to liquefaction of the entire basal layer. These apoptotic changes may also be a reflection of the disease activity [128].

Ragaz and Ackerman noted an increased number of Langerhans cells in the epidermis very early in the disease process [99]. These cells function to present the autoantigens or foreign antigens to T-cells prior to T-cell activation. Langerhans cells are more prevalent in OLP lesions than healthy oral mucosa and the degree of migration of these cells from the superficial layers to the basal layer may be a predictor of disease chronicity [129]. 
TABLE 5: The pattern of DIF results of potential differential diagnoses of lichen planus.

\begin{tabular}{ll}
\hline Differential & DIF pattern \\
\hline Lichen planus & Globular IgM and fibrin deposition at BMZ \\
Aphthous ulcers & Negative \\
Bullous pemphigoid & Linear C3, IgG at BMZ, less common IgA \\
Chronic ulcerative stomatitis & Speckled or granular perinuclear IgG in the lower third and basal layer of epithelium \\
Dermatitis herpetiformis & Granular IgA at BMZ with concentration at the papillary tips \\
Discoid lupus erythematosus & Linear band or continuous granular IgG, IgA, IgM, and C3 at BMZ \\
Epidermolysis bullosa acquisita & Linear IgG and C3 at BMZ \\
Erythema multiforme & Negative \\
Hailey-Hailey disease & Negative \\
Lichen nitidus & Negative \\
Linear IgA bullous dermatosis & Linear IgA at BMZ, less common IgG, IgM, and C3 \\
Mucous membrane pemphigoid & Linear IgG and C3 at BMZ, less common IgA, IgM, and/or fibrin \\
Paraneoplastic pemphigus & Intercellular IgG and C3 with or without BMZ involvement \\
Pemphigus vulgaris & Intercellular IgG (IgG1 and IgG4) in "chicken wire pattern," less common C3 and IgM \\
Systemic lupus erythematosus & Linear band or continuous granular IgG, IgA, IgM, and C3 at BMZ \\
\hline
\end{tabular}

BMZ: basement membrane zone; DIF: direct immunofluorescence; Ig: immunoglobulin.

\section{Etiology and Risk Factors}

4.1. Immunogenetic Factors. LP is a complex disease and thus can be caused or triggered by genetic malfunction and/or environmental factors. The existence of familial cases of LP may suggest a possible genetic predisposition [130, 131]. Gene polymorphisms of different HLA markers as well as the inflammatory cytokines and chemokines have been associated with the presence of LP (Table 6). The causality of these polymorphisms, although unclear, supports the autoantigen hypothesis.

4.2. Clinical Factors. Associated factors and disease conditions seen in LP include but are not limited to stress/anxiety, hepatitis $\mathrm{C}$ virus ( $\mathrm{HCV})$, autoimmune diseases, internal malignancies, dyslipidemia, and viral infections. Anxiety is a well-established risk factor or accompanying factor in LP patients [132]. Some studies have indicated that stressful events can induce LP lesions in otherwise healthy individuals. In a case-control study, more than $67 \%$ of LP patients experienced a stressful event while about $21 \%$ of matched healthy controls experienced such events [133]. Other studies more or less indicate a similar trend for stress, anxiety, and depression $[134,135]$. Table 7 summarizes the coexistence of some clinical conditions and LP.

We performed a meta-analysis to find the potential association between LP and HCV including all studies in previously published meta-analyses [136-138] and new studies [139-143], which investigated the prevalence of HCV in LP patients compared with a control population. Based on data pooling of 64 studies, LP patients have 5.58 times the odds of having concurrent $\mathrm{HCV}$ infection than the control population (95\% CI: 3.72-8.38, $P<0.05$ ).

In an attempt to investigate the role of HPV in the pathogenesis of OLP, Syrjänen et al. [144] performed a metaanalysis. They found statistically remarkable and significant odds ratios for HPV, in general, and HPV-16 (5.12 (95\%
CI: $2.40-10.93)$ and 5.61 (95\% CI: 2.42-12.99), resp.). This finding suggests that HPV has a higher prevalence in OLP patients than the normal population; it may have a role in the malignant transformation of OLP lesions [145]. Erosive OLP and hypertrophic CLP are considered as the main subtypes with malignant potential $[20,146]$.

A systematic search revealed three studies [189-191] that compared the prevalence of the transfusion transmitted virus or Torque tenovirus (TTV) in LP versus disease-control patients or healthy volunteers. TTV is the only member of Anelloviridae [192]. After performing a meta-analysis using two studies [190, 191], there was no significant difference between LP and healthy control groups (odds ratio of 1.13 [95\% CI: 0.67-1.89], $P>0.05)$. Fehér et al. [190] recently showed that genogroup 1 TTV-not TTV in general-is significantly more common in OLP patients $(10.1 \%)$ when compared to the control group (1.4\%). This group hypothesized that genogroup 1 TTV is correlated with the immunoinflammatory response in OLP patients. They also evaluated the subtypes and genotypes of TTV in the aforementioned patients and noted some differences in OLP lesions and normal skin samples from the same patients [193].

While the varicella zoster virus is rare in OLP patients $[194,195]$, a recent study noted a significant role for the virus in zosteriform LP but not in linear LP [196].

LP patients are at increased risk of developing dyslipidemia, with an adjusted odds ratio of 2.85 (95\% CI, 1.335.09; $P=0.001$ ) [197]. However, patients with hyperglycemia and/or hypertension are not at risk [197].

\section{Quality of Life}

Quality of life questionnaires are easy and practical tools to quantify the impact of a disease based on the patient's perception. There are a large number of general and dermatologyrelated quality of life questionnaires including the Dermatology Life Quality Index (DLQI), which is a widely used 
TABLE 6: Suggested gene polymorphisms that are associated with LP.

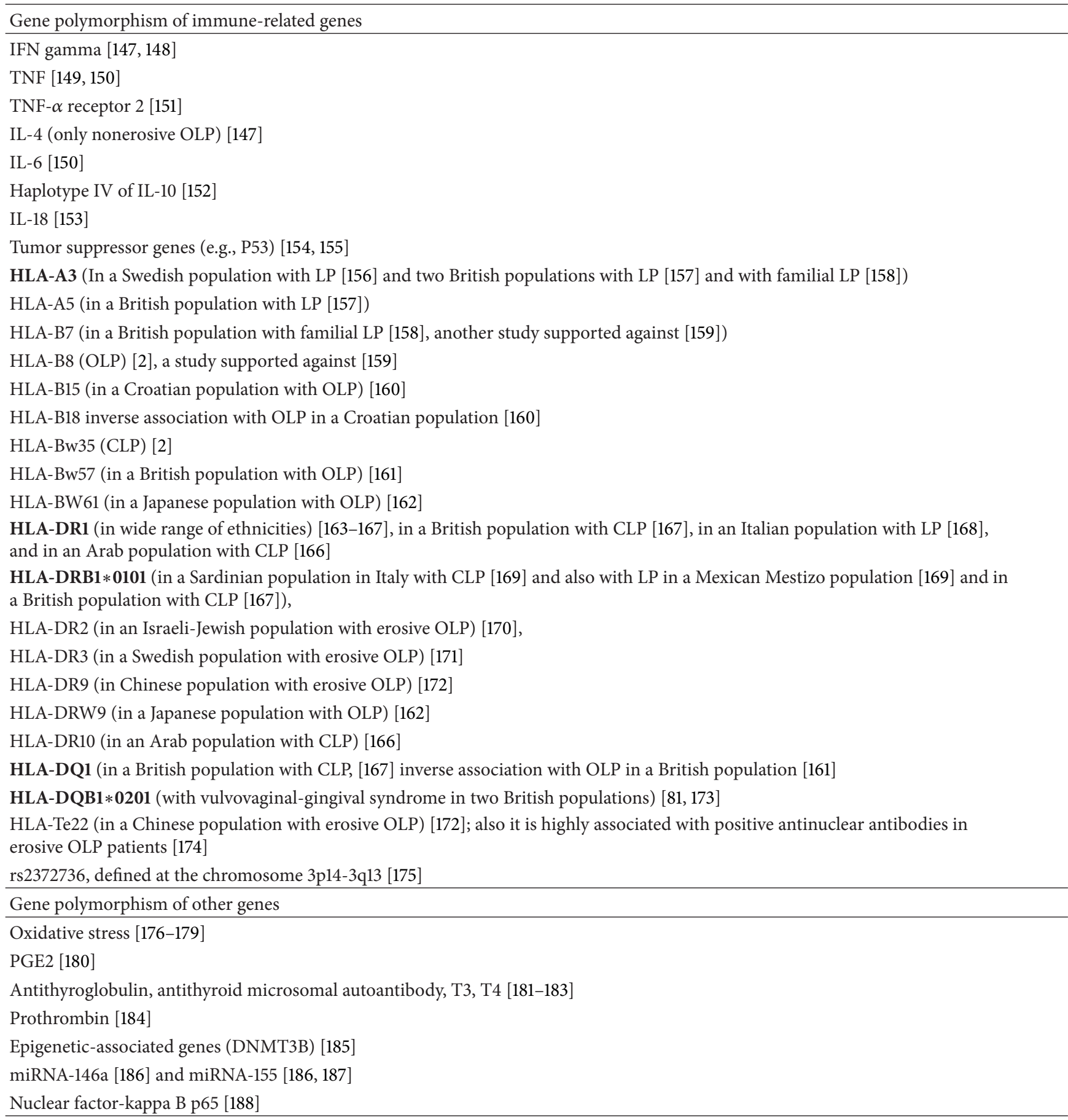

The ones in bold are considered more prevalent than the others.

dermatology specific quality of life instrument [276]. LP was comparable to psoriasis with regard to Dermatology Life Quality Index (DLQI) scores of $9.60 \pm 7.32$ versus $9.50 \pm 6.10$, respectively. Additionally, OLP patients had a significantly higher DLQI score when compared to CLP patients (13.27 \pm 8.05 versus $7.47 \pm 6.11$ ) [277]. The Oral Health Impact Profile (OHIP) is a 49 item quality of life questionnaire to evaluate the social impact of oral disorders which is based on theoretical hierarchy of oral health outcomes [278]. OLP was found to have a significant impact on psychological discomfort and social disability, using OHIP 49 item questionnaire [279]. Furthermore, OLP seems to have a higher impact on patients' quality of life than recurrent aphthous stomatitis but lower impact as compared to oral bullous diseases [280]. There is also a correlation between increase in pain evaluated by visual analogue scoring and poor oral 
TABLE 7: Clinical associations of LP.

Cutaneous diseases

Chronic graft versus host disease [198-200]

Alopecia areata [201, 202]

Pemphigus vulgaris [203]

Paraneoplastic pemphigus [204]

Dermatitis herpetiformis [205, 206]

Bullous pemphigoid [207-209]

Atopic dermatitis [23]

Psoriasis [210]

Vitiligo [211-213]

Morphea [214-217]

Dermatomyositis [218]

Lichen sclerosus et atrophicus [215, 219-221]

\section{Other diseases}

Liver disease [201, 222] (primary biliary cirrhosis, [223-225]

primary sclerosing cholangitis [226])

HCV infection [138, 142, 227]

EBV infection [228-230]

HPV infection [145, 230-232]

HHV-7 [230, 233, 234]

Ulcerative colitis [201, 202]

Chronic gastritis, Helicobacter pylori [77, 235-237]

Dyslipidemia [197, 238, 239]

Anxiety [132, 135, 240-250] or stress [20, 251]

Depression [132, 134, 135, 241, 242, 244-250, 252-255]

Celiac disease [256-259]

Myasthenia gravis and thymoma [260-266],

Systemic lupus erythematosus [267-270]

Sjögren's syndrome [271, 272]

Multiple sclerosis [273]

Hypothyroidism [274]

Hashimoto thyroiditis

Verruciform xanthoma [275]

health-related quality of life in patients with LP [281]. Patients with erosive OLP or generalized LP may have poor quality of life because of the associated pain and discomfort.

5.1. Prognosis. Typically, CLP lesions resolve within 6 months to a year. However, the hypertrophic variant, if left untreated, tends to persist for years. Untreated reticular OLP has a chronic or progressive nature, usually without complete resolution. LP can also have a recurrent pattern. Patients with erosive LP may experience changes in location and severity of the disease with waxing and waning cycles of concurrent healing and lesion formation. Although generalized LP tends to heal faster than other variants, it has a greater likelihood of relapse [2]. LPP can be progressive in its course with destruction of hair follicles leading to atrophic cicatricial alopecia [43].

5.2. Carcinogenic Transformation. The carcinogenic potential of OLP lesions has been a longstanding topic of debate. When loss of heterozygosity and microsatellite instability were investigated as two of the main indicators for malignant transformation, OLP was not different from benign fibroma, but it was significantly different from low-grade oral dysplasia, high-grade oral dysplasia, and oral SCC [282]. Vered et al. clearly suggested a widespread proinflammatory response rather than a protumorigenic response [283]. Similar to other malignancies, the elderly are at increased risk for developing SCC [284] and tend to have more severe forms of the disease [285].

The epidemiology surrounding OLP and its inherent risk of oral squamous cell carcinoma remains poorly defined. A question, that has yet to be answered, is whether the associated risk of malignant transformation is intrinsic to the OLP lesions or as a result of the patient's immune response or genetic background. There is no proper surrogate biomarker for OLP malignant transformation. Shi et al. suggested the co-expression of podoplanin and ATP-binding cassette transporter G2 (ABCG2) as a higher prognostic marker with a significant odds ratio (25.24, 95\% CI: 4.48142.27, $P<0.001$ ) [284]. Unfortunately, podoplanin is not sensitive or specific, as it can be expressed even in normal skin [286]. Additionally, ABCG2 is expressed in various organs and has a major role in tissue repair [287] in addition to chemoresistance of different tumors [288]. Another marker, c-Jun, a member of activating protein-1 transcription factor family, was present in 11 out of 12 LP patients and in all SCC patients while not expressed remarkably in normal patients. These transcription factors contribute to cell proliferation and thus they may be indications of LP's carcinogenic potential [289]. These reports should be interpreted cautiously due to the small sample size and lack of prospective follow-up. The literature is still inconclusive in this regard except for the fact that it seems improbable that OLP is inherently carcinogenic [290].

The malignant transformation rate of vulvar LP and esophageal LP seems to be $1.1 \%$ [73] and 5.5\% [76], respectively. In a cohort study with no healthy controls and without correcting the odds ratio for premalignant viral diseases, 8 of 327 OLP patients $(2.4 \%)$ developed oral SCC in previously affected areas. Interestingly, this was not correlated with immunosuppressive therapy in those patients [291]. The transformation ratio for OLP lesions varies from $0.8 \%$ in an American population [20] to more than 5\% in an Italian cohort [292]. This ratio appears to be no more than $1 \%$ for OLP over 5 years [293]. Nonetheless, this estimated rate does not match the prevalence of OLP and oral cancer. Indeed, an OLP prevalence of $1 \%$ and a transformation rate of $0.2 \%$ per year would mean that almost every single oral SCC should arise from an OLP lesion. Hence, this theory was refuted as few accompanying OLP lesions were detected in oral SCC patients [293-296]. Further investigation of whether chronic 
LP is a premalignant condition would necessitate large-scale prospective cohort studies with a long-term follow-up period.

\section{Conclusions}

LP is a T-cell mediated disease. The prevalence of LP is less than $5 \%$ with no evident sexual predilection. The chronic and often erosive nature of LP can have detrimental effects on patients' quality of life. Erosive-ulcerative OLP lesions tend to become painful and chronic and vulvar LP may interfere with sexual intercourse and can be associated with significant psychological and physical morbidity. HCV and HPV are more prevalent in LP patients compared to the normal population. The carcinogenic potential of OLP lesions remains debatable.

\section{Abbreviations}

$\begin{array}{ll}\text { ABCG2: } & \text { ATP-binding cassette transporter G2 } \\ \text { CLP: } & \text { Cutaneous lichen planus } \\ \text { DIF: } & \text { Direct immunofluorescence } \\ \text { DLE: } & \text { Discoid lupus erythematosus } \\ \text { FFA: } & \text { Frontal fibrosing alopecia } \\ \text { HCV: } & \text { Hepatitis C virus } \\ \text { HPV: } & \text { Human papillomavirus } \\ \text { LP: } & \text { Lichen planus } \\ \text { LPP: } & \text { Lichen planopilaris } \\ \text { MF: } & \text { Mycosis fungoides } \\ \text { NK cells: } & \text { Natural killer cells } \\ \text { OLP: } & \text { Oral lichen planus } \\ \text { SCC: } & \text { Squamous cell carcinoma } \\ \text { Th: } & \text { T helper } \\ \text { TLR: } & \text { Toll-like receptor. }\end{array}$

\section{Conflict of Interests}

There is no conflict of interests.

\section{Acknowledgments}

The authors truly thank Dr. John Harris for his valuable revisions. They are indeed indebted to Dr. Peter Lynch and Dr. Omid Zargari for providing contributing photos to this manuscript. They would also like to thank Dr. Irina Lejkina for her contribution in translating the Russian literature.

\section{References}

[1] V. Kumar, A. Abbas, and J. Aster, Robbins \& Cotran Pathologic Basis of Disease, Saunders, Philadelphia, Pa, USA, 8th ed edition, 2009.

[2] M. Daoud and M. Pittelkow, "Lichen Planusin," in Fitzpatrick's Dermatology in General Medicine, L. Goldsmith, S. I. Katz, B. A. Gilchrest, A. S. Paller, D. J. Leffell, and K. Wolff, Eds., McGrawHill, New York, NY, USA, 2012.

[3] E. Wilson, "On leichen planus," Journal of Cutaneous Medicine and Surgery, vol. 3, no. 10, pp. 117-132, 1869.
[4] J. J. Pindborg, P. A. Reichart, and C. I. Smith, "WHO international histological classification of tumours," in Histological Typing of Cancer and Precancer of the Oral Mucosa, J. J. Pindborg, P. A. Reichart, and C. I. Smith, Eds., Springer, Berlin, Germany, 1997.

[5] H. W. Stelwagon, Treatise on Diseases of the Skin for the Use of Advanced Students and Practitioners, W. B. Sauders, Philadelphia, Pa, USA, 7th edition, 1914.

[6] A. Weyl, "Bemerkungen zum Lichen Planus," Deutsche Medizinische Wochenschrift, vol. 11, pp. 624-626, 1885.

[7] L. F. Wickham, "Sur un signe pathognomonique du lichen de Wilson (lichen plan) Stries et ponctuations grisatres," Annales de Dermatologie et de Syphiligraphie, vol. 6, pp. 517-520, 1895.

[8] J. Darier, Precis de Dermatologie, Masson, Paris, France, 1909.

[9] H. Gougerot and R. Burnier, "Lichen plan du col uterin, accompagnant un lichen plan jugal et un lichen plan stomacal: lichen plurimuqueux sans lichen cutane," Bulletin de la Société Française de Dermatologie et de Syphiligraphie, vol. 44, pp. 637640, 1937.

[10] M. Pelisse, M. Leibowitch, D. Sedel, and J. Hewitt, "A new vulvovagino-gingival syndrome. Mucosal erosive Lichen Planus," Annales de Dermatologie et de Venereologie, vol. 109, no. 9, pp. 797-798, 1982.

[11] T. Shiohara and Y. Kano, "Lichen Planus and lichenoid dermatoses," in Dermatology, J. L. Bolognia, J. Jorizzo, and R. P. Rapini, Eds., pp. 159-180, Mosby Elsevier, New York, NY, USA, 2008.

[12] C. S. Miller, J. B. Epstein, E. H. Hall, and D. Sirois, "Changing oral care needs in the United States: the continuing need for oral medicine," Oral Surgery, Oral Medicine, Oral Pathology, Oral Radiology, and Endodontics, vol. 91, no. 1, pp. 34-44, 2001.

[13] J. E. Bouquot and R. J. Gorlin, "Leukoplakia, Lichen Planus, and other oral keratoses in 23,616 white Americans over the age of 35 years," Oral Surgery Oral Medicine and Oral Pathology, vol. 61, no. 4, pp. 373-381, 1986.

[14] T. Axéll and L. Rundquist, "Oral Lichen Planus-a demographic study," Community Dentistry and Oral Epidemiology, vol. 15, no. 1, pp. 52-56, 1987.

[15] G. O. Alabi and J. B. Akinsanya, "Lichen Planus in tropical Africa," Tropical and Geographical Medicine, vol. 33, no. 2, pp. 143-147, 1981.

[16] B. J. Schlosser, "Lichen Planus and lichenoid reactions of the oral mucosa," Dermatologic Therapy, vol. 23, no. 3, pp. 251-267, 2010.

[17] B. E. McCartan and C. M. Healy, "The reported prevalence of oral Lichen Planus: a review and critique," Journal of Oral Pathology and Medicine, vol. 37, no. 8, pp. 447-453, 2008.

[18] M. Carrozzo, "How common is oral Lichen Planus?" EvidenceBased Dentistry, vol. 9, no. 4, pp. 112-113, 2008.

[19] R. S. Pannell, D. M. Fleming, and K. W. Cross, "The incidence of molluscum contagiosum, scabies and Lichen Planus," Epidemiology and Infection, vol. 133, no. 6, pp. 985-991, 2005.

[20] D. Eisen, "The clinical features, malignant potential, and systemic associations of oral Lichen Planus: a study of 723 patients," Journal of the American Academy of Dermatology, vol. 46, no. 2, pp. 207-214, 2002.

[21] R. Sharma and V. Maheshwari, "Childhood Lichen Planus: a report of fifty cases," Pediatric Dermatology, vol. 16, no. 5, pp. 345-348, 1999.

[22] A. J. Kanwar and D. De, "Lichen Planus in childhood: report of 100 cases," Clinical and Experimental Dermatology, vol. 35, no. 3, pp. 257-262, 2010. 
[23] K. E. Walton, E. V. Bowers, B. A. Drolet, and K. E. Holland, "Childhood Lichen Planus: demographics of a U.S. population," Pediatric Dermatology, vol. 27, no. 1, pp. 34-38, 2010.

[24] A. J. Kanwar, S. Dogra, S. Handa, D. Parsad, and B. D. Radotra, "A study of 124 Indian patients with Lichen Planus pigmentosus," Clinical and Experimental Dermatology, vol. 28, no. 5, pp. 481-485, 2003.

[25] S. M. Salman, A.-G. Kibbi, and S. Zaynoun, "Actinic Lichen Planus. A clinicopathologic study of 16 patients," Journal of the American Academy of Dermatology, vol. 20, no. 2, part 1, pp. 226-231, 1989.

[26] E. Tan, M. Martinka, N. Ball, and J. Shapiro, "Primary cicatricial alopecias: clinicopathology of 112 cases," Journal of the American Academy of Dermatology, vol. 50, no. 1, pp. 25-32, 2004.

[27] F. Gorouhi, A. Firooz, A. Khatami et al., "Interventions for cutaneous Lichen Planus," Cochrane Database of Systematic Reviews, no. 4, Article ID CD008038, 2009.

[28] J. P. Welsh, C. B. Skvarka, and H. B. Allen, "A novel visual clue for the diagnosis of hypertrophic Lichen Planus," Archives of Dermatology, vol. 142, no. 7, p. 954, 2006.

[29] E. Willsteed, B. S. Bhogal, A. K. Das, F. Wojnarowska, M. M. Black, and P. H. McKee, "Lichen Planus pemphigoides: a clinicopathological study of nine cases," Histopathology, vol. 19, no. 2, pp. 147-154, 1991.

[30] J. Santos-Juanes, A. Mas-Vidal, P. Coto-Segura, J. Sánchez Del Río, and C. Galache Osuna, "Pigmented actinic Lichen Planus successfully treated with intense pulsed light," British Journal of Dermatology, vol. 163, no. 3, pp. 662-663, 2010.

[31] I. Dekio, S. Matsuki, M. Furumura, E. Morita, and A. Morita, "Actinic Lichen Planus in a Japanese man: first case in the East Asian population," Photodermatology Photoimmunology and Photomedicine, vol. 26, no. 6, pp. 333-335, 2010.

[32] H. L. Reich, J. T. Nguyen, and W. D. James, "Annular Lichen Planus: a case series of 20 patients," Journal of the American Academy of Dermatology, vol. 50, no. 4, pp. 595-599, 2004.

[33] T. Badri, N. Kenani, R. Benmously, A. Debbiche, I. Mokhtar, and S. Fenniche, "Isolated genital annular, Lichen Planus," Acta Dermatovenerologica Alpina, Pannonica et Adriatica, vol. 20, no. 1, pp. 31-33, 2011.

[34] A. Morales-Callaghan Jr., G. Martínez, H. Aragoneses, and A. Miranda-Romero, "Annular atrophic Lichen Planus," Journal of the American Academy of Dermatology, vol. 52, no. 5, pp. 906908, 2005.

[35] P. Batra, N. Wang, H. Kamino, and P. Possick, "Linear Lichen Planus," Dermatology Online Journal, vol. 14, no. 10, p. 16, 2008.

[36] D. Perry and N. Fazel, "Zosteriform Lichen Planus," Dermatology Online Journal, vol. 12, no. 5, p. 3, 2006.

[37] R. Happle, "Linear Lichen Planus of the face and neck versus amalgam-induced "isotopic" cutaneous Lichen Planus," Journal of the American Academy of Dermatology, vol. 52, no. 2, p. 375, 2005.

[38] S. K. Ghosh, D. Bandyopadhyay, G. Chatterjee, and D. Saha, "Wolf's isotopic response: large annular polycyclic Lichen Planus occurring on healed lesions of dermatophytosis," Journal of the European Academy of Dermatology and Venereology, vol. 23, no. 3, pp. 355-356, 2009.

[39] N. Ohshima, A. Shirai, I. Saito, and A. Asahina, "Lichen Planus pigmentosus-inversus occurring extensively in multiple intertriginous areas," Journal of Dermatology, vol. 39, no. 4, pp. 412-414, 2012.
[40] E. Gaertner and W. Elstein, "Lichen Planus pigmentosusinversus: case report and review of an unusual entity, Dermatology Online Journal, vol. 18, no. 2, p. 11, 2012.

[41] H. Kang, A. A. Alzolibani, N. Otberg, and J. Shapiro, "Lichen planopilaris," Dermatologic Therapy, vol. 21, no. 4, pp. 249-256, 2008.

[42] P. Assouly and P. Reygagne, "Lichen planopilaris: update on diagnosis and treatment," Seminars in Cutaneous Medicine and Surgery, vol. 28, no. 1, pp. 3-10, 2009.

[43] D. A. Mehregan, H. M. Van Hale, and S. A. Muller, "Lichen planopilaris: clinical and pathologic study of forty-five patients," Journal of the American Academy of Dermatology, vol. 27, no. 6, part 1, pp. 935-942, 1992.

[44] K. Gunduz, T. Sacar, I. Inanir, and P. Demireli, "Flexural follicular Lichen Planus," Clinical and Experimental Dermatology, vol. 34, no. 7, pp. e297-e298, 2009.

[45] Y.Z. Chiang, A. Tosti, I. H. Chaudhry et al., "Lichen planopilaris following hair transplantation and face-lift surgery," British Journal of Dermatology, vol. 166, no. 3, pp. 666-670, 2012.

[46] M. R. Crisóstomo, M. G. R. Crisóstomo, M. R. Crisóstomo, M. C. C. Crisóstomo, V. J. T. Gondim, and A. N. Benevides, "Hair loss due to lichen planopilaris after hair transplantation: a report of two cases and a literature review," Anais Brasileiros de Dermatologia, vol. 86, no. 2, pp. 359-362, 2011.

[47] M. S. Zinkernagel and R. M. Trüeb, "Fibrosing alopecia in a pattern distribution: patterned lichen planopilaris or androgenetic alopecia with a lichenoid tissue reaction pattern?" Archives of Dermatology, vol. 136, no. 2, pp. 205-211, 2000.

[48] S. Kossard, M.-S. Lee, and B. Wilkinson, "Postmenopausal frontal fibrosing alopecia: a frontal variant of lichen planopilaris," Journal of the American Academy of Dermatology, vol. 36, no. 1, pp. 59-66, 1997.

[49] V. V. Pai, N. Kikkeri, T. Sori, and U. S. Dinesh, "Graham-little piccardi lassueur syndrome: an unusual variant of follicular Lichen Planus," International Journal of Trichology, vol. 3, no. 1, pp. 28-30, 2011.

[50] P. Davari, F. Gorouhi, and N. Fazel, "Treatment of lichen planus," in Evidence Based Dermatology, H. Maibach and F. Gorouhi, Eds., PMPH-USA, Shelton, Conn, USA, 2nd edition, 2011.

[51] J. Sánchez-Pérez, L. R. Buceta, J. Fraga, and A. García-Díez, "Lichen Planus with lesions on the palms and/or soles: prevalence and clinicopathological study of 36 patients," British Journal of Dermatology, vol. 142, no. 2, pp. 310-314, 2000.

[52] M. J. Kim, M. Choi, S. Y. Na, J. H. Lee, and S. Cho, "Two cases of palmoplantar Lichen Planus with various clinical features," Journal of Dermatology, vol. 37, no. 11, pp. 985-989, 2010.

[53] A. Tosti, B. M. Piraccini, S. Cambiaghi, and M. Jorizzo, "Nail Lichen Planus in children: clinical features, response to treatment, and long-term follow-up," Archives of Dermatology, vol. 137, no. 8, pp. 1027-1032, 2001.

[54] A. Tosti, B. M. Piraccini, S. Cambiaghi, and M. Jorizzo, "Nail Lichen Planusin," in Color Atlas of Nails, pp. 83-85, Springer, Berlin, Germany, 2010.

[55] H. Yokozeki, S. Niiyama, and K. Nishioka, "Twenty-nail dystrophy (trachyonychia) caused by Lichen Planus in a patient with gold allergy," The British Journal of Dermatology, vol. 152, no. 5, pp. 1087-1089, 2005.

[56] S. Taniguchi, H. Kutsuna, Y. Tani, K. Kawahira, and T. Hamada, "Twenty-nail dystrophy (trachyonychia) caused by Lichen Planus in a patient with alopecia universalis and ichthyosis vulgaris," Journal of the American Academy of Dermatology, vol. 33, no. 5, part 2, pp. 903-905, 1995. 
[57] E. N. Nnoruka, "Lichen Planus in African children: a study of 13 patients," Pediatric Dermatology, vol. 24, no. 5, pp. 495-498, 2007.

[58] B. Richert, M. Iorizzo, A. Tosti, and J. André, "Nail bed Lichen Planus associated with onychopapilloma," British Journal of Dermatology, vol. 156, no. 5, pp. 1071-1072, 2007.

[59] L. Juhlin and R. Baran, "On longitudinal melanonychia after healing of Lichen Planus," Acta Dermato-Venereologica, vol. 70, no. 2, p. 183, 1990.

[60] D. Eisen, "The evaluation of cutaneous, genital, scalp, nail, esophageal, and ocular involvement in patients with oral Lichen Planus," Oral Surgery, Oral Medicine, Oral Pathology, Oral Radiology, and Endodontics, vol. 88, no. 4, pp. 431-436, 1999.

[61] F. A. de Sousa and L. E. B. Rosa, "Oral Lichen Planus: clinical and histopathological considerations," Brazilian Journal of Otorhinolaryngology, vol. 74, no. 2, pp. 284-292, 2008.

[62] J. J. Thorn, P. Holmstrup, J. Rindum, and J. J. Pindborg, "Course of various clinical forms of oral Lichen Planus. A prospective follow-up study of 611 patients," Journal of Oral Pathology, vol. 17, no. 5, pp. 213-218, 1988.

[63] S. L. Bricker, "Oral Lichen Planus: a review," Seminars in Dermatology, vol. 13, no. 2, pp. 87-90, 1994.

[64] N. Mollaoglu, "Oral Lichen Planus: a review," British Journal of Oral and Maxillofacial Surgery, vol. 38, no. 4, pp. 370-377, 2000.

[65] D. J. Zegarelli, “The treatment of oral Lichen Planus," Annals of Dentistry, vol. 52, no. 2, pp. 3-8, 1993.

[66] S. V. Lourenço, A. C. B. Resende, S. B. Bologna, and M. M. S. Nico, "Lichen Planus sialadenitis: a mucosal analog of lichen planopilaris and lichen planoporitis," Journal of Cutaneous Pathology, vol. 37, no. 3, pp. 396-399, 2010.

[67] T. McPherson and S. Cooper, "Vulval lichen sclerosus and Lichen Planus," Dermatologic Therapy, vol. 23, no. 5, pp. 523$532,2010$.

[68] J. Schorge, J. Schaffer, and L. Halvorson, Williams Gynecology, McGraw-Hill, Philadelphia, Pa, USA, 1st edition, 2008.

[69] F. M. Lewis, "Vulval Lichen Planus," British Journal of Dermatology, vol. 138, no. 4, pp. 569-575, 1998.

[70] S. M. Cooper and F. Wojnarowska, "Influence of treatment of erosive Lichen Planus of the vulva on its prognosis," Archives of Dermatology, vol. 142, no. 3, pp. 289-294, 2006.

[71] A. T. Goldstein and A. Metz, "Vulvar Lichen Planus," Clinical Obstetrics and Gynecology, vol. 48, no. 4, pp. 818-823, 2005.

[72] A. L. O. Helgesen, P. Gjersvik, P. Jebsen, R. Kirschner, and T. Tanbo, "Vaginal involvement in genital erosive Lichen Planus," Acta Obstetricia et Gynecologica Scandinavica, vol. 89, no. 7, pp. 966-970, 2010.

[73] R. C. Simpson, S. M. Littlewood, S. M. Cooper et al., "Reallife experience of managing vulval erosive Lichen Planus: a case-based review and U.K. multicentre case note audit," British Journal of Dermatology, vol. 167, no. 1, pp. 85-91, 2012.

[74] P. Belfiore, O. Di Fede, D. Cabibi et al., "Prevalence of vulval Lichen Planus in a cohort of women with oral Lichen Planus: an interdisciplinary study," British Journal of Dermatology, vol. 155, no. 5, pp. 994-998, 2006.

[75] M. A. Ramer, A. Altchek, L. Deligdisch, R. Phelps, A. Montazem, and P. M. Buonocore, "Lichen Planus and the vulvovaginal-gingival syndrome," Journal of Periodontology, vol. 74, no. 9, pp. 1385-1393, 2003.

[76] L. P. Fox, C. J. Lightdale, and M. E. Grossman, "Lichen Planus of the esophagus: what dermatologists need to know," Journal of the American Academy of Dermatology, vol. 65, no. 1, pp. 175183, 2011.

[77] B. Izol, A. A. Karabulut, I. Biyikoglu, M. Gonultas, and M. Eksioglu, "Investigation of upper gastrointestinal tract involvement and H. pylori presence in Lichen Planus: a case controlled study with endoscopic and histopathological findings," International Journal of Dermatology, vol. 49, no. 10, pp. 1121-1126, 2010.

[78] D. A. Katzka, T. C. Smyrk, A. J. Bruce, Y. Romero, J. A. Alexander, and J. A. Murray, "Variations in presentations of esophageal involvement in Lichen Planus," Clinical Gastroenterology and Hepatology, vol. 8, no. 9, pp. 777-782, 2010.

[79] B. Şanli, E. N. Çetin, F. Bir, L. Taşli, F. Yaldizkaya, and V. Yaylali, "Conjunctival impression cytology, ocular surface and tear-film changes in patients with Lichen Planus," Clinical and Experimental Dermatology, 2012.

[80] M. K. Rhee and V. V. Mootha, "Bilateral Keratoconjunctivitis Associated with Lichen Planus," Cornea, vol. 23, no. 1, pp. 100105, 2004.

[81] N. K. Webber, J. F. Setterfield, F. M. Lewis, and S. M. Neill, "Lacrimal canalicular duct scarring in patients with Lichen Planus," Archives of Dermatology, vol. 148, no. 2, pp. 224-227, 2012.

[82] R. Sharma and N. Singhal, "Lichen Planus of the eyelids. A report of 5 cases," Dermatology Online Journal, vol. 7, no. 1, p. $5,2001$.

[83] S. B. Verma, "Lichen Planus affecting eyelid alone: a rare entity," Indian Journal of Dermatology, Venereology and Leprology, vol. 72, no. 5, p. 398, 2006.

[84] M. B. Crosby, C. V. Crosby, T. H. Wojno, and H. E. Grossniklaus, "Conjunctival Lichen Planus in a patient with herpes simplex virus keratitis," Cornea, vol. 28, no. 8, pp. 936-937, 2009.

[85] J. C. Ramos-Esteban, L. Schoenfield, and A. D. Singh, "Conjunctival Lichen Planus simulating ocular surface squamous neoplasia," Cornea, vol. 28, no. 10, pp. 1181-1183, 2009.

[86] E. R. Muñoz, M. E. Martínez-Escala, N. Juanpere, J. Armentia, R. M. Pujol, and J. E. Herrero-González, "Isolated conjunctival Lichen Planus: a diagnostic challenge," Archives of Dermatology, vol. 147, no. 4, pp. 465-467, 2011.

[87] M. Pakravan, T. R. Klesert, and E. K. Akpek, "Isolated Lichen Planus of the conjunctiva," British Journal of Ophthalmology, vol. 90, no. 10, pp. 1325-1326, 2006.

[88] M. Mehta, S. S. Siddique, L. A. Gonzalez-Gonzalez, and C. S. Foster, "Immunohistochemical differences between normal and chronically inflamed conjunctiva: diagnostic features," American Journal of Dermatopathology, vol. 33, no. 8, pp. 786789, 2011.

[89] J. E. Thorne, D. A. Jabs, O. V. Nikolskaia, D. Mimouni, G. J. Anhalt, and H. C. Nousari, "Lichen Planus and cicatrizing conjunctivitis: characterization of five cases," American Journal of Ophthalmology, vol. 136, no. 2, pp. 239-243, 2003.

[90] J. D. Brewer, N. S. Ekdawi, R. R. Torgerson et al., "Lichen Planus and cicatricial conjunctivitis: disease course and response to therapy of 11 patients," Journal of the European Academy of Dermatology and Venereology, vol. 25, no. 1, pp. 100-104, 2011.

[91] C. E. Rennie, R. C. Dwivedi, A. S. Khan, N. Agrawal, and W. Ziyada, "Lichen Planus of the larynx," Journal of Laryngology and Otology, vol. 125, no. 4, pp. 432-435, 2011.

[92] Z. I. Shaikh, A. Arfan-ul-Bari, A. A. Mashhood, A. Qayyum, and L. Latif-ur-Rahman, "Mucosal Lichen Planus simultaneously involving oral mucosa, conjunctiva and larynx," Journal of the College of Physicians and Surgeons Pakistan, vol. 20, no. 7, pp. 478-479, 2010. 
[93] V. Kunelskaya Ya. and A. M. Arievich, "Affection of the laryngeal mucosa in lichen ruber planus striatus," Vestnik Oto-RinoLaringologii, vol. 40, no. 5, pp. 32-35, 1978.

[94] K. J. Busm, Dermatopathology: A Volume in the Foundations in Diagnostic Pathology Series, Expert Consult-Online and Print, Saunders, New York, NY, USA, 1st edition, 2009.

[95] G. Laskaris, A. Sklavounou, and A. Angelopoulos, "Direct immunofluorescence in oral Lichen Planus," Oral Surgery Oral Medicine and Oral Pathology, vol. 53, no. 5, pp. 483-487, 1982.

[96] D. E. Elder, R. Elenitsas, B. L. Johnson, G. F. Murphy, and X. $\mathrm{Xu}$, Lever's Histopathology of the Skin, Lippincott Williams \& Wilkins, Philadelphia, Pa, USA, 10th edition, 2008.

[97] H. Gougerot and A. Civatte, "Clinical and histologic criteria of cutaneous and mucosal Lichen Planus; delimitation," Annales de Dermatologie et de Syphiligraphie, vol. 80, no. 1, pp. 5-29, 1953.

[98] F. A. Ellis, "Histopathology of Lichen Planus based on analysis of one hundred biopsy specimens," Journal of Investigative Dermatology, vol. 48, no. 2, pp. 143-148, 1967.

[99] A. Ragaz and A. B. Ackerman, "Evolution, maturation, and regression of lesions of Lichen Planus. New observations and correlations of clinical and histologic findings," American Journal of Dermatopathology, vol. 3, no. 1, pp. 5-25, 1981.

[100] E. Moscarella, S. González, M. Agozzino et al., "Pilot study on reflectance confocal microscopy imaging of Lichen Planus: a real-time, non-invasive aid for clinical diagnosis," Journal of the European Academy of Dermatology and Venereology, vol. 26, no. 10, pp. 1258-1265, 2012.

[101] N. Mobini, S. Tam, and H. Kamino, "Possible role of the bulge region in the pathogenesis of inflammatory scarring alopecia: Lichen planopilaris as the prototype," Journal of Cutaneous Pathology, vol. 32, no. 10, pp. 675-679, 2005.

[102] G. Shklar, "Erosive and bullous oral lesions of Lichen Planus: histologic studies," Archives of Dermatology, vol. 97, no. 4, pp. 411-416, 1968.

[103] D. Lage, P. B. Juliano, K. Metze, E. M. D. Souza, and M. L. Cintra, "Lichen Planus and lichenoid drug-induced eruption: a histological and immunohistochemical study," International Journal of Dermatology, vol. 51, no. 10, pp. 1199-1205, 2012.

[104] S. Halevy and A. Shai, "Lichenoid drug eruptions," Journal of the American Academy of Dermatology, vol. 29, no. 2, part 1, pp. 249-255, 1993.

[105] J. A. Yiannias, R. A. El-Azhary, J. H. Hand, S. Y. Pakzad, and R. S. Rogers III, "Relevant contact sensitivities in patients with the diagnosis of oral Lichen Planus," Journal of the American Academy of Dermatology, vol. 42, no. 2, part 1, pp. 177-182, 2000.

[106] P. N. Athavale, K. W. Shum, C. M. Yeoman, and D. J. Gawkrodger, "Oral lichenoid lesions and contact allergy to dental mercury and gold," Contact Dermatitis, vol. 49, no. 5, pp. 264-265, 2003.

[107] M. J. Lartitegui-Sebastian, B. Martínez-Revilla, C. Saiz-Garcia, S. Eguizabal-Saracho, and J. M. Aguirre-Urizar, "Oral lichenoid lesions associated with amalgam restorations: a prospective pilot study addressing the adult population of the Basque Country," Medicina Oral, Patologia Oral, Cirugia Bucal, vol. 17, no. 4, pp. e545-e549, 2012.

[108] R. S. Rogers III and A. J. Bruce, "Lichenoid contact stomatitis: is inorganic mercury the culprit?" Archives of Dermatology, vol. 140, no. 12, pp. 1524-1525, 2004.

[109] C. M. Allen and G. G. Blozis, "Oral mucosal reactions to cinnamon-flavored chewing gum," The Journal of the American Dental Association, vol. 116, no. 6, pp. 664-667, 1988.
[110] S. Gunatheesan, M. M. Tam, B. Tate, J. Tversky, and R. Nixon, "Retrospective study of oral Lichen Planus and allergy to spearmint oil," Australasian Journal of Dermatology, vol. 53, no. 3, pp. 224-228, 2012.

[111] J. Guitart, M. Peduto, W. A. Caro, and H. H. Roenigk, "Lichenoid changes in mycosis fungoides," Journal of the American Academy of Dermatology, vol. 36, no. 3, part 1, pp. 417-422, 1997.

[112] M. E. Vega, L. Waxtein, R. Arenas, M. T. Hojyo, and L. Dominguez-Soto, "Ashy dermatosis and Lichen Planus pigmentosus: a clinicopathologic study of 31 cases," International Journal of Dermatology, vol. 31, no. 2, pp. 90-94, 1992.

[113] G. M. White and N. H. Cox, Diseases of the Skin. A Color Atlas and Text, Mosby, New York, NY, USA, 2nd edition, 2006.

[114] D. S. Waldorf, "Lichen planopilaris. Histopathologic study of disease. Progression to scarring alopedia," Archives of Dermatology, vol. 93, no. 6, pp. 684-691, 1966.

[115] J. M. Grant-Kels, Color Atlas of Dermatopathology (Dermatology: Clinical \& Basic Science), Informa Healthcare, San Francisco, NC, USA, 1st edition, 2007.

[116] B. D. Estrada, C. Tamler, C. T. Sodré, C. B. Barcaui, and F. B. C. Pereira, "Dermoscopy patterns of cicatricial alopecia resulting from discoid lupus erythematosus and lichen planopilaris," Anais Brasileiros de Dermatologia, vol. 85, no. 2, pp. 179-183, 2010.

[117] D. J. Gawkrodger, P. G. Stavropoulos, K. M. McLaren, and P. K. Buxton, "Bullous Lichen Planus and Lichen Planus pemphigoides-clinico-pathological comparisons," Clinical and Experimental Dermatology, vol. 14, no. 2, pp. 150-153, 1989.

[118] E. T. Bope, R. D. Kellerman, and R. R. E. Bope, Conn'S Current Therapy 2011, Elsevier Saunders, Philadelphia, Pa, USA, 2011.

[119] M. Ichimura, K. Hiratsuka, N. Ogura et al., "Expression profile of chemokines and chemokine receptors in epithelial cell layers of oral Lichen Planus," Journal of Oral Pathology and Medicine, vol. 35, no. 3, pp. 167-174, 2006.

[120] W. Iijima, H. Ohtani, T. Nakayama et al., "Infiltrating CD8+ T cells in oral Lichen Planus predominantly express CCR5 and CXCR3 and carry respective chemokine ligands RANTES/CCL5 and IP-10/CXCL10 in their cytolytic granules: a potential self-recruiting mechanism," American Journal of Pathology, vol. 163, no. 1, pp. 261-268, 2003.

[121] U. Spandau, A. Toksoy, M. Goebeler, E. Bröcker, and R. Gillitzer, "MIG is a dominant lymphocyte-attractant chemokine in Lichen Planus lesions," Journal of Investigative Dermatology, vol. 111, no. 6, pp. 1003-1009, 1998.

[122] S. B. Janardhanam, S. Prakasam, V. T. Swaminathan, K. N. Kodumudi, S. L. Zunt, and M. Srinivasan, "Differential expression of TLR-2 and TLR-4 in the epithelial cells in oral Lichen Planus," Archives of Oral Biology, vol. 57, no. 5, pp. 495-502, 2012.

[123] M. Siponen, J. H. Kauppila, Y. Soini, and T. Salo, "TLR4 and TLR9 are induced in oral Lichen Planus," Journal of Oral Pathology \& Medicine, vol. 41, no. 10, pp. 741-747, 2012.

[124] T. Carbone, F. Nasorri, D. Pennino et al., "CD56highCD16- NK cell involvement in cutaneous Lichen Planus," European Journal of Dermatology, vol. 20, no. 6, pp. 724-730, 2010.

[125] L. Lei, W. X. Tan, X. L. Zhou, and P. E. Zheng, "Expression of Fas and Fas ligand in infiltrating lymphocytes in patients with oral Lichen Planus," Zhonghua Kou Qiang Yi Xue Za Zhi, vol. 45, no. 4, pp. 219-222, 2010.

[126] M. Hadzi-Mihailovic, H. Raybaud, R. Monteil, and L. Jankovic, "Expression of Fas/FasL in patients with oral Lichen Planus," Journal of B.U.ON., vol. 14, no. 3, pp. 487-493, 2009. 
[127] A. Santoro, A. Majorana, E. Bardellini et al., "Cytotoxic molecule expression and epithelial cell apoptosis in oral and cutaneous Lichen Planus," American Journal of Clinical Pathology, vol. 121, no. 5, pp. 758-764, 2004.

[128] J. M. C. Brant, A. C. Vasconcelos, and L. V. Rodrigues, "Role of apoptosis in erosive and reticular oral Lichen Planus exhibiting variable epithelial thickness," Brazilian Dental Journal, vol. 19, no. 3, pp. 179-185, 2008.

[129] A. Pandey, S. Setty, R. Rao, and R. Radhakrishnan, "Assessment of Langerhans cells in oral Lichen Planus by ATPase histochemistry: a clinicopathologic correlation," Quintessence International, vol. 42, no. 3, pp. 225-234, 2011.

[130] A. Bermejo-Fenoll and P. López-Jornet, "Familial oral Lichen Planus: presentation of six families," Oral Surgery, Oral Medicine, Oral Pathology, Oral Radiology and Endodontology, vol. 102, no. 2, pp. e12-e15, 2006.

[131] A. Singal, "Familial mucosal Lichen Planus in three successive generations," International Journal of Dermatology, vol. 44, no. 1, pp. 81-82, 2005.

[132] C. Girardi, C. Luz, K. Cherubini, M. A. Z. D. Figueiredo, M. L. T. Nunes, and F. G. Salum, "Salivary cortisol and dehydroepiandrosterone (DHEA) levels, psychological factors in patients with oral Lichen Planus," Archives of Oral Biology, vol. 56, no. 9, pp. 864-868, 2011.

[133] L. Manolache, D. Seceleanu-Petrescu, and V. Benea, "Lichen Planus patients and stressful events," Journal of the European Academy of Dermatology and Venereology, vol. 22, no. 4, pp. 437-441, 2008.

[134] K. Mohamadi Hasel, M. A. Besharat, A. Abdolhoseini, S. Alaei Nasab, and S. Niknam, "Relationships of personality factors to perceived stress, depression, and oral Lichen Planus severity," International Journal of Behavioral Medicine, pp. 1-7, 2012.

[135] M. J. García-Pola Vallejo, G. Huerta, R. Cerero, and J. M. Seoane, "Anxiety and depression as risk factors for oral Lichen Planus," Dermatology, vol. 203, no. 4, pp. 303-307, 2001.

[136] S. Liu, S. Yao, W. Wei, W. Tian, H. Zhang, and B. Wang, "Hepatitis $\mathrm{C}$ virus and Lichen Planus: a reciprocal association determined by a meta-analysis," Archives of Dermatology, vol. 145, no. 9, pp. 1040-1047, 2009.

[137] G. Lodi, M. Giuliani, A. Majorana et al., "Lichen Planus and hepatitis C virus: a multicentre study of patients with oral lesions and a systematic review," British Journal of Dermatology, vol. 151, no. 6, pp. 1172-1181, 2004.

[138] G. Lodi, R. Pellicano, and M. Carrozzo, "Hepatitis C virus infection and Lichen Planus: a systematic review with metaanalysis," Oral Diseases, vol. 16, no. 7, pp. 601-612, 2010.

[139] L. Lin, S. Lu, and S. Lu, "Seroprevalence of anti-HCV among patients with oral Lichen Planus in Southern Taiwan," Oral Surgery, Oral Medicine, Oral Pathology, Oral Radiology and Endodontology, vol. 109, no. 3, pp. 408-414, 2010.

[140] Y. Zhou, L. Jiang, J. Liu, X. Zeng, and Q. Chen, “The prevalence of hepatitis $C$ virus infection in oral Lichen Planus in an ethnic Chinese cohort of 232 patients," International Journal of Oral Science, vol. 2, no. 2, pp. 90-97, 2010.

[141] M. Halawani, A. Balbisi, H. Alotaibi, F. Alsaif, and T. M. Bakir, "The prevalence of HCV antibodies in skin disease patients in Saudi Arabia," Saudi Pharmaceutical Journal, vol. 18, no. 1, pp. 35-39, 2010.

[142] K. Rubsam, A. Schroll, P. Weisenseel, S. Multhaup, T. Ruzicka, and J. C. Prinz, "Lichen Planus and hepatitis virus infections: causal association?" Journal der Deutschen Dermatologischen Gesellschaft, vol. 9, no. 6, pp. 464-468, 2011.
[143] S. Birkenfeld, J. Dreiher, D. Weitzman, and A. D. Cohen, "A study on the association with hepatitis B and hepatitis C in 1557 patients with Lichen Planus," Journal of the European Academy of Dermatology and Venereology, vol. 25, no. 4, pp. 436-440, 2011.

[144] S. Syrjänen, G. Lodi, I. von Bültzingslöwen et al., "Human papillomaviruses in oral carcinoma and oral potentially malignant disorders: a systematic review," Oral Diseases, vol. 17, supplement 1, pp. 58-72, 2011.

[145] M. Gorsky and J. B. Epstein, "Oral Lichen Planus: malignant transformation and human papilloma virus: a review of potential clinical implications," Oral Surgery, Oral Medicine, Oral Pathology, Oral Radiology and Endodontology, vol. 111, no. 4, pp. 461-464, 2011.

[146] B. Sigurgeirsson and B. Lindelof, "Lichen Planus and malignancy: an epidemiologic study of 2071 patients and a review of the literature," Archives of Dermatology, vol. 127, no. 11, pp. 1684$1688,1991$.

[147] J. Bai, M. Lin, X. Zeng et al., "Association of polymorphisms in the human IFN- $\gamma$ and IL-4 gene with oral Lichen Planus: a study in an ethnic Chinese cohort," Journal of Interferon and Cytokine Research, vol. 28, no. 6, pp. 351-358, 2008.

[148] I. Kimkong, J. Nakkuntod, P. Sodsai, N. Hirankarn, and N. Kitkumthorn, "Association of interferon-gamma gene polymorphisms with susceptibility to oral Lichen Planus in the Thai population," Archives of Oral Biology, vol. 57, no. 5, pp. 491-494, 2012.

[149] I. Kimkong, N. Hirankarn, J. Nakkuntod, and N. Kitkumthorn, "Tumour necrosis factor-alpha gene polymorphisms and susceptibility to oral Lichen Planus," Oral Diseases, vol. 17, no. 2, pp. 206-209, 2011.

[150] G. M. Xavier, A. R. D. Sá, A. L. S. Guimarães, T. A. D. Silva, and R. S. Gomez, "Investigation of functional gene polymorphisms interleukin- $1 \beta$, interleukin-6, interleukin-10 and tumor necrosis factor in individuals with oral Lichen Planus," Journal of Oral Pathology and Medicine, vol. 36, no. 8, pp. 476-481, 2007.

[151] H. Fujita, T. Kobayashi, H. Tai et al., "Assessment of 14 functional gene polymorphisms in Japanese patients with oral Lichen Planus: a pilot case-control study," International Journal of Oral and Maxillofacial Surgery, vol. 38, no. 9, pp. 978-983, 2009.

[152] J. Bai, L. Jiang, M. Lin, X. Zeng, Z. Wang, and Q. Chen, "Association of polymorphisms in the tumor necrosis factor- $\alpha$ and interleukin-10 genes with oral Lichen Planus: a study in a Chinese cohort with Han ethnicity," Journal of Interferon and Cytokine Research, vol. 29, no. 7, pp. 381-387, 2009.

[153] J. Bai, Y. Zhang, M. Lin et al., "Interleukin-18 gene polymorphisms and haplotypes in patients with oral Lichen Planus: a study in an ethnic Chinese cohort," Tissue Antigens, vol. 70, no. 5, pp. 390-397, 2007.

[154] P. Yanatatsaneeji, N. Kitkumthorn, C. Dhammawipark, J. Rabalert, V. Patel, and A. Mutirangura, "Codon72 polymorphism in the p53 tumor suppressor gene in oral Lichen Planus lesions in a Thai population," Asian Pacific Journal of Cancer Prevention, vol. 11, no. 4, pp. 1137-1141, 2010.

[155] M. Schifter, A. M. Jones, and D. M. Walker, "Epithelial p53 gene expression and mutational analysis, combined with growth fraction assessment, in oral Lichen Planus," Journal of Oral Pathology and Medicine, vol. 27, no. 7, pp. 318-324, 1998.

[156] N. K. Veien, G. Risum, H. P. Jorgensen, and A. Svejgaard, "HLA antigens in patients with Lichen Planus," Acta DermatoVenereologica, vol. 59, no. 3, pp. 205-209, 1979. 
[157] N. J. Lowe, A. G. Cudworth, and J. C. Woodrow, "HL A antigens in Lichen Planus," British Journal of Dermatology, vol. 95, no. 2, pp. 169-171, 1976.

[158] P. W. M. Copeman, R. S. H. Tan, D. Timlin, and P. D. Samman, "Familial Lichen Planus. Another disease or a distinct people?" British Journal of Dermatology, vol. 98, no. 5, pp. 573-577, 1978.

[159] E. D. A. Potts and N. R. Rowell, "Lichen Planus: a distinct entity from lupus erythematosus," Acta Dermato-Venereologica, vol. 61, no. 5, pp. 413-416, 1981.

[160] M. Ognjenovic, D. Karelović, M. Mikelić, I. Tadin, and V. Vrebalov-Cindro, "Oral Lichen Planus and HLA B," Coll Antropol, vol. 22, pp. 93-96, 1998.

[161] K. Porter, P. Klouda, C. Scully, J. Bidwell, and S. R. Porter, "Class I and II HLA antigens in British patients with oral Lichen Planus," Oral Surgery Oral Medicine and Oral Pathology, vol. 75, no. 2, pp. 176-180, 1993.

[162] T. Watanabe, M. Ohishi, K. Tanaka, and H. Sato, "Analysis of HLA antigens in Japanese with oral Lichen Planus," Journal of Oral Pathology, vol. 15, no. 10, pp. 529-533, 1986.

[163] F. C. Powell, R. S. Rogers, E. R. Dickson, and S. Breanndan Moore, "An association between HLA DR1 and Lichen Planus," British Journal of Dermatology, vol. 114, no. 4, pp. 473-478, 1986.

[164] R. Valsecchi, M. Bontempelli, P. M. Bellavita et al., "HLA-DR1 and lichen ruber planus," Giornale Italiano di Dermatologia e Venereologia, vol. 122, no. 6, pp. 277-280, 1987.

[165] C. Carcassi, F. Cottoni, L. Floris et al., "The HLA-DRB1(*)0101 allele is responsible for HLA susceptibility to lichen ruber planus," European Journal of Immunogenetics, vol. 21, no. 6, pp. 425-429, 1994.

[166] A. G. White and A. I. Rostom, "HLA antigens in Arabs with Lichen Planus," Clinical and Experimental Dermatology, vol. 19, no. 3, pp. 236-237, 1994.

[167] G. La Nasa, F. Cottoni, M. Mulargia et al., "HLA antigen distribution in different clinical subgroups demonstrates genetic heterogeneity in Lichen Planus," British Journal of Dermatology, vol. 132, no. 6, pp. 897-900, 1995.

[168] R. Valsecchi, M. Bontempelli, A. Rossi et al., "HLA-DR and DQ antigens in Lichen Planus," Acta Dermato-Venereologica, vol. 68, no. 1, pp. 77-80, 1988.

[169] P. Luis-Montoya, J. K. Yamamoto-Furusho, E. Vega-Memije et al., "HLA-DRB $1 * 0101$ is associated with the genetic susceptibility to develop Lichen Planus in the Mexican Mestizo population," Archives of Dermatological Research, vol. 299, no. 8, pp. 405-407, 2007.

[170] A. Roitberg-Tambur, A. Friedmann, S. Korn et al., "Serologic and molecular analysis of the HLA system in Israeli Jewish patients with oral erosive Lichen Planus," Tissue Antigens, vol. 43, no. 4, pp. 219-223, 1994.

[171] M. Jontell, P. A. Ståhlblad, I. Rosdahl, and B. Lindblom, "HLA-DR3 antigens in erosive oral Lichen Planus, cutaneous Lichen Planus, and lichenoid reactions," Acta Odontologica Scandinavica, vol. 45, no. 5, pp. 309-312, 1987.

[172] S.-C. Lin and A. Sun, "HLA-DR and DQ antigens in Chinese patients with oral Lichen Planus," Journal of Oral Pathology and Medicine, vol. 19, no. 7, pp. 298-300, 1990.

[173] J. F. Setterfield, S. Neill, P. J. Shirlaw et al., "The vulvovaginal gingival syndrome: a severe subgroup of Lichen Planus with characteristic clinical features and a novel association with the class II HLA DQB1*0201 allele," Journal of the American Academy of Dermatology, vol. 55, no. 1, pp. 98-113, 2006.
[174] A. Sun, Y. C. Wu, J. T. Wang, B. Y. Liu, and C. P. Chiang, "Association of HLA-te22 antigen with anti-nuclear antibodies in Chinese patients with erosive oral Lichen Planus," Proceedings of the National Science Council, Republic of China B, vol. 24, no. 2, pp. 63-69, 2000.

[175] Z. Wang, H. Yao, B. Cui, G. Ning, and G. Y. Tang, "Genetic linkage analysis of oral Lichen Planus in a Chinese family," Genetics and Molecular Research, vol. 10, no. 3, pp. 1427-1433, 2011.

[176] E. Sezer, F. Ozugurlu, H. Ozyurt, S. Sahin, and I. Etikan, "Lipid peroxidation and antioxidant status in Lichen Planus," Clinical and Experimental Dermatology, vol. 32, no. 4, pp. 430-434, 2007.

[177] I. Scrobotǎ, T. Mocan, C. Cătoi, P. Bolfă, A. Mureşan, and G. Băciuţ, "Histopathological aspects and local implications of oxidative stress in patients with oral Lichen Planus," Romanian Journal of Morphology and Embryology, vol. 52, no. 4, pp. 13051309, 2011.

[178] S. G. Sapuntsova, O. A. Lebed'ko, M. V. Shchetkina, M. Y. Fleyshman, E. A. Kozulin, and S. S. Timoshin, "Status of freeradical oxidation and proliferation processes in patients with atopic dermatitis and Lichen Planus," Bulletin of Experimental Biology and Medicine, vol. 150, no. 6, pp. 690-692, 2011.

[179] R. B. Upadhyay, S. Carnelio, R. P. Shenoy, P. Gyawali, and M. Mukherjee, "Oxidative stress and antioxidant defense in oral Lichen Planus and oral lichenoid reaction," Scandinavian Journal of Clinical and Laboratory Investigation, vol. 70, no. 4, pp. 225-228, 2010.

[180] R. M. Abdel Hay, M. M. Fawzy, D. Metwally et al., "DNA polymorphisms and tissue cyclooxygenase- 2 expression in oral Lichen Planus: a case-control study," Journal of the European Academy of Dermatology and Venereology, vol. 26, no. 9, pp. 1122-1126, 2012.

[181] D. Compilato, C. Paderni, O. Di Fede, G. Gulotta, and G. Campisi, "Association of oral Lichen Planus with thyroid disease in a Finnish population: a retrospective case-control study:, 'A different finding from a Mediterranean area,' Oral Surgery, Oral Medicine, Oral Pathology, Oral Radiology, and Endodontology, vol. 111, no. 1, pp. 12-14, 2011.

[182] J. Y. Chang, C. Chiang, C. K. Hsiao, and A. Sun, "Significantly higher frequencies of presence of serum autoantibodies in Chinese patients with oral Lichen Planus," Journal of Oral Pathology and Medicine, vol. 38, no. 1, pp. 48-54, 2009.

[183] H. Lin, Y. Wang, J. Chia, and A. Sun, "Modulation of serum antithyroglobulin and anti-thyroid microsomal autoantibody levels by levamisole in patients with oral Lichen Planus," Journal of the Formosan Medical Association, vol. 110, no. 3, pp. 169-174, 2011.

[184] A. Wankiewicz, I. Iwan-Ziętek, and D. Rość, "Chosen blood coagulation parameters in patients with Lichen Planus," Polski Merkuriusz Lekarski, vol. 16, no. 97, pp. 55-57, 2004.

[185] T. Fonseca-Silva, M. V. M. De Oliveira, C. A. D. C. Fraga et al., "DNMT3B (C46359T) polymorphisms and immunoexpression of DNMT3b and DNMT1 proteins in oral Lichen Planus," Pathobiology, vol. 79, no. 1, pp. 18-23, 2012.

[186] T. C. Arão, A. L. S. Guimarães, A. M. B. de Paula, C. C. Gomes, and R. S. Gomez, "Increased miRNA-146a and miRNA-155 expressions in oral Lichen Planus," Archives of Dermatological Research, pp. 1-5, 2011.

[187] A. Terlou, L. A. M. Santegoets, W. I. Van Der Meijden et al., "An autoimmune phenotype in vulvar lichen sclerosus and Lichen Planus: a Th1 response and high levels of microRNA155," Journal of Investigative Dermatology, vol. 132, no. 3, pp. 658-666, 2012. 
[188] G. Zhou, K. Xia, G. Du et al., "Activation of nuclear factorkappa B correlates with tumor necrosis factor-alpha in oral Lichen Planus: a clinicopathologic study in atrophic-erosive and reticular form," Journal of Oral Pathology and Medicine, vol. 38, no. 7, pp. 559-564, 2009.

[189] E. Rodriguez-Inigo, J. J. Arrieta, M. Casqueiro et al., "TT virus detection in oral Lichen Planus lesions," Journal of Medical Virology, vol. 64, no. 2, pp. 183-189, 2001.

[190] E. Fehér, T. Gáll, M. Murvai et al., "Investigation of the occurrence of torque tenovirus in malignant and potentially malignant disorders associated with human papillomavirus," Journal of Medical Virology, vol. 81, no. 11, pp. 1975-1981, 2009.

[191] C. Bez, R. Hallett, M. Carrozzo et al., "Lack of association between hepatotropic transfusion transmitted virus infection and oral Lichen Planus in British and Italian populations," British Journal of Dermatology, vol. 145, no. 6, pp. 990-993, 2001.

[192] T. Nishizawa, H. Okamoto, K. Konishi, H. Yoshizawa, Y. Miyakawa, and M. Mayumi, "A novel DNA virus (TTV) associated with elevated transaminase levels in posttransfusion hepatitis of unknown etiology," Biochemical and Biophysical Research Communications, vol. 241, no. 1, pp. 92-97, 1997.

[193] E. Fehér, G. Kardos, T. Gáll, A. Kis, L. Gergely, and K. Szarka, "Comparison of diversity of torque teno virus 1 in different mucosal tissues and disorders," Acta Microbiologica et Immunologica Hungarica, vol. 58, no. 4, pp. 319-337, 2011.

[194] F. Ghodratnama, M. P. Riggio, and D. Wray, "Search for human herpesvirus 6, human cytomegalovirus and varicella zoster virus DNA in recurrent aphthous stomatitis tissue," Journal of Oral Pathology and Medicine, vol. 26, no. 4, pp. 192-197, 1997.

[195] F. Ghodratnama, D. Wray, and J. Bagg, "Detection of serum antibodies against cytomegalovirus, varicella zoster virus and human herpesvirus 6 in patients with recurrent aphthous stomatitis," Journal of Oral Pathology and Medicine, vol. 28, no. 1, pp. 12-15, 1999.

[196] R. P. Braun, D. Barua, and I. Masouye, "Zosteriform Lichen Planus after herpes zoster," Dermatology, vol. 197, no. 1, pp. 8788, 1998.

[197] S. Arias-Santiago, A. Buenda-Eisman, J. Aneiros-Fernndez et al., "Cardiovascular risk factors in patients with Lichen Planus," American Journal of Medicine, vol. 124, no. 6, pp. 543-548, 2011.

[198] R. Touraine, J. Revuz, B. Dreyfus, H. Rochant, and P. Mannoni, "Graft versus host reaction and Lichen Planus," British Journal of Dermatology, vol. 92, no. 5, p. 589, 1975.

[199] J. H. Saurat, L. Didier-Jean, E. Gluckman, and A. Bussel, "Graft versus host reaction and Lichen Planus-like eruption in man," British Journal of Dermatology, vol. 92, no. 5, pp. 591-592, 1975.

[200] J. H. Saurat, "Lichen Planus and graft versus host disease," Giornale Italiano di Dermatologia e Venereologia, vol. 117, no. 6, pp. 369-370, 1982.

[201] "Study of Lichen Planus conducted by the IGESD: results, implications for clinical practice, prospects. Italian Group of Epidemiological Studies in Dermatology (IGESD)," Giornale Italiano di Dermatologia e Venereologia, vol.125, no. 12, pp. 563$567,1990$.

[202] T. Cainelli, "Epidemiological evidence of the association between Lichen Planus and two immune-related diseases. Alopecia areata and ulcerative colitis," Archives of Dermatology, vol. 127, no. 5, pp. 688-691, 1991.

[203] C. W. Lee, H. Hur, and J. I. Youn, "Pemphigus vulgaris coexisting with generalized Lichen Planus," Journal of Dermatology, vol. 14, no. 4, pp. 388-391, 1987.
[204] S. R. Stevens, C. E. M. Griffiths, G. J. Anhalt, and K. D. Cooper, "Paraneoplastic pemphigus presenting as a Lichen Planus pemphigoides-like eruption," Archives of Dermatology, vol. 129, no. 7, pp. 866-869, 1993.

[205] A. G. Pratt, "Dermatitis herpetiformis followed by lesions resembling Lichen Planus," Archives of Dermatology and Syphilology, vol. 53, p. 664, 1946.

[206] E. I. Bologa and F. Vaida, "Lichen ruber planus in regression with following Duhring's dermatitis herpetiformis," Dermatologische Monatsschrift, vol. 157, no. 6, pp. 447-452, 1971.

[207] G. Stingl and K. Holubar, "Coexistence of Lichen Planus and bullous pemphigoid. An immunopathological study," British Journal of Dermatology, vol. 93, no. 3, pp. 313-320, 1975.

[208] S. I. Rekant, "Lichen Planus and bullous pemphigoid," Archives of Dermatology, vol. 112, no. 11, p. 1613, 1976.

[209] N. J. Collins and J. P. Dowling, "Lichen Planus and bullous pemphigoid," Australasian Journal of Dermatology, vol. 23, no. 1, pp. 9-13, 1982.

[210] N. Ohshima, A. Shirai, and A. Asahina, "Coexistence of linear Lichen Planus and psoriasis in a single patient," Journal of Dermatology, vol. 38, no. 12, pp. 1182-1184, 2011.

[211] U. Gül, S. Soylu, and M. Demiriz, "Colocalization of Lichen Planus and vitiligo associated with selective IgA deficiency," Skinmed, vol. 6, no. 4, pp. 202-203, 2007.

[212] H. Ujiie, D. Sawamura, and H. Shimizu, "Development of Lichen Planus and psoriasis on lesions of vitiligo vulgaris," Clinical and Experimental Dermatology, vol. 31, no. 3, pp. 375377, 2006.

[213] K. Sardana, R. C. Sharma, R. V. Koranne, and S. Mahajan, "An interesting case of colocalization of segmental Lichen Planus and vitiligo in a 14-year-old boy," International Journal of Dermatology, vol. 41, no. 8, pp. 508-509, 2002.

[214] M. Melato, N. Gorji, C. Rizzardi, and M. Maglione, "Associated localization of morphea and Lichen Planus of the lip in a patient with vitiligo," Minerva Stomatologica, vol. 49, no. 11-12, pp. 549$554,2000$.

[215] D. Sawamura, T. Yaguchi, I. Hashimoto, K. Nomura, R. Konta, and K. Umeki, "Coexistence of generalized morphea with histological changes in lichen sclerosus et atrophicus and Lichen Planus," Journal of Dermatology, vol. 25, no. 6, pp. 409-411, 1998.

[216] M. G. Connelly and K. Winkelmann r., "Coexistence of lichen sclerosus, morphea, and Lichen Planus: report of four cases and review of the literature," Journal of the American Academy of Dermatology, vol. 12, no. 5, part 1, pp. 844-851, 1985.

[217] W. Brenner, E. Diem, and F. Gschnait, "Coincidence of vitiligo, alopecia areata, onychodystrophy, localized scleroderma and Lichen Planus," Dermatologica, vol. 159, no. 4, pp. 356-360, 1979.

[218] A. Al-Najjar, G. D. Reilly, and C. I. Harrington, "Dermatomyositis and Lichen Planus-an association or manifestation?" Clinical and Experimental Dermatology, vol. 10, no. 2, pp. 174$178,1985$.

[219] S. C. Holmes and A. D. Burden, "Lichen sclerosus and Lichen Planus: a spectrum of disease?" Clinical and Experimental Dermatology, vol. 23, no. 3, pp. 129-131, 1998.

[220] A. Bazex, R. Salvador, A. Dupre, M. Parant, and B. Christol, "Lichen sclerosus et atrophicus and Lichen Planus sclerosus," Bulletin de la Société française de dermatologie et de syphiligraphie, vol. 70, pp. 450-451, 1963.

[221] R. A. C. Graham-Brown and I. Sarkany, "Lichen sclerosus et atrophicus: with primary biliary cirrhosis and Lichen Planus," International Journal of Dermatology, vol. 25, no. 5, p. 317, 1986. 
[222] "Lichen Planus and liver diseases: a multicentre case-control study. Gruppo Italiano Studi Epidemiologici in Dermatologia (GISED)," British Medical Journal, vol. 300, no. 6719, pp. 227230, 1990.

[223] R. A. C. Graham-Brown, I. Sarkany, and S. Sherlock, "Lichen Planus and primary biliary cirrhosis," British Journal of Dermatology, vol. 106, no. 6, pp. 699-703, 1982.

[224] F. C. Powell, R. S. Rogers III, and E. R. Dickson, "Primary biliary cirrhosis and Lichen Planus," Journal of the American Academy of Dermatology, vol. 9, no. 4, pp. 540-545, 1983.

[225] C.-Y. Chu, C.-Y. Yang, S.-F. Huang, S.-C. Lu, and L.-F. Wang, "Lichen Planus with xanthomatous change in a patient with primary biliary cirrhosis," British Journal of Dermatology, vol. 142, no. 2, pp. 377-378, 2000.

[226] D. C. Tong and M. M. Ferguson, "Concurrent oral Lichen Planus and primary sclerosing cholangitis," British Journal of Dermatology, vol. 147, no. 2, pp. 356-358, 2002.

[227] A. Rebora, "Hcv and Lichen Planus," Hepatitis Monthly, vol. 11, no. 2, pp. 134-135, 2011.

[228] L. P. Sand, J. Jalouli, P. Larsson, and J. Hirsch, "Prevalence of Epstein-Barr virus in oral squamous cell carcinoma, oral Lichen Planus, and normal oral mucosa," Oral Surgery, Oral Medicine, Oral Pathology, Oral Radiology, and Endodontics, vol. 93, no. 5, pp. 586-592, 2002.

[229] A. Pedersen, "Abnormal EBV immune status in oral Lichen Planus," Oral Diseases, vol. 2, no. 2, pp. 125-128, 1996.

[230] C. ÓFlatharta, S. R. Flint, M. Toner, D. Butler, and M. J. E. M. F. Mabruk, "Investigation into a possible association between oral Lichen Planus, the human herpesviruses, and the human papillomaviruses," Molecular Diagnosis, vol. 7, no. 2, pp. 73-83, 2003.

[231] S. M. Razavi, P. Ghalayani, M. R. Salehi, H. Attarzadeh, and M. Shahmoradi, "Human papilloma virus as a possible factor in the pathogenesis of oral Lichen Planus," Journal of Dental Research, vol. 6, no. 2, pp. 82-86, 2009.

[232] S. P. Khovidhunkit, W. Buajeeb, S. Sanguansin, S. Poomsawat, and W. Weerapradist, "Detection of human papillomavirus in oral squamous cell carcinoma, leukoplakia and Lichen Planus in Thai patients," Asian Pacific Journal of Cancer Prevention, vol. 9, no. 4, pp. 771-775, 2008.

[233] H. J. C. De Vries, M. B. M. Teunissen, F. Zorgdrager, D. Picavet, and M. Cornelissen, "Lichen Planus remission is associated with a decrease of human herpes virus type 7 protein expression in plasmacytoid dendritic cells," Archives of Dermatological Research, vol. 299, no. 4, pp. 213-219, 2007.

[234] H. J. C. De Vries, J. Van Marle, M. B. M. Teunissen et al., "Lichen Planus is associated with human herpesvirus type 7 replication and infiltration of plasmacytoid dendritic cells," British Journal of Dermatology, vol. 154, no. 2, pp. 361-364, 2006.

[235] E. Vainio, S. Huovinen, M. Liutu, J. Uksila, and R. Leino, "Peptic ulcer and Helicobacter pylori in patients with Lichen Planus," Acta Dermato-Venereologica, vol. 80, no. 6, pp. 427-429, 2000.

[236] E. Dauden, M. A. Vázquez-Carrasco, P. F. Peñas, J. M. Pajares, and A. García-Díez, "Association of Helicobacter pylori infection with psoriasis and Lichen Planus: prevalence and effect of eradication therapy," Archives of Dermatology, vol. 136, no. 10, pp. 1275-1276, 2000.

[237] E. A. S. Attia, N. S. A. Abdel Fattah, and H. M. Abdella, "Upper gastrointestinal findings and detection of Helicobacter pylori in patients with oral Lichen Planus: clinical dermatology • Original article," Clinical and Experimental Dermatology, vol. 35, no. 4, pp. 355-360, 2010.
[238] J. Dreiher, J. Shapiro, and A. D. Cohen, "Lichen Planus and dyslipidaemia: a case-control study," British Journal of Dermatology, vol. 161, no. 3, pp. 626-629, 2009.

[239] S. Arias-Santiago, A. Buendía-Eisman, and J. AneirosFernández, "Lipid levels in patients with Lichen Planus: a case-control study," Journal of the European Academy of Dermatology and Venereology, vol. 25, no. 12, pp. 1398-1401, 2011.

[240] C. Camisa, C. M. Allen, B. Bowen, and R. G. Olsen, "Indirect immunofluorescence of oral Lichen Planus," Journal of Oral Pathology, vol. 15, no. 4, pp. 218-220, 1986.

[241] S. Chaudhary, "Psychosocial stressors in oral Lichen Planus," Australian Dental Journal, vol. 49, no. 4, pp. 192-195, 2004.

[242] G. Colella, P. Gritti, F. De Luca, and M. de Vito, "The psychopathological aspects of oral Lichen Planus (OLP)," Minerva Stomatologica, vol. 42, no. 6, pp. 265-270, 1993.

[243] M. Koray, O. Dülger, G. Ak et al., "The evaluation of anxiety and salivary cortisol levels in patients with oral Lichen Planus," Oral Diseases, vol. 9, no. 6, pp. 298-301, 2003.

[244] E. N. Lundqvist, Y. B. Wahlin, M. Bergdahl, and J. Bergdahl, "Psychological health in patients with genital and oral erosive Lichen Planus," Journal of the European Academy of Dermatology and Venereology, vol. 20, no. 6, pp. 661-666, 2006.

[245] B. E. McCartan, "Psychological factors associated with oral Lichen Planus," Journal of oral Pathology \& Medicine, vol. 24, no. 6, pp. 273-275, 1995.

[246] J. S. G. Pokupec, V. Gruden, and V. Gruden Jr., "Lichen ruber planus as a psychiatric problem," Psychiatria Danubina, vol. 21, no. 4, pp. 514-516, 2009.

[247] J. L. Rojo-Moreno, J. V. Bagán, J. Rojo-Moreno, J. S. Donat, M. A. Milián, and Y. Jiménez, "Psychologic factors and oral Lichen Planus: a psychometric evaluation of 100 cases," Oral Surgery, Oral Medicine, Oral Pathology, Oral Radiology, and Endodontics, vol. 86, no. 6, pp. 687-691, 1998.

[248] B. Shah, L. Ashok, and G. P. Sujatha, "Evaluation of salivary cortisol and psychological factors in patients with oral Lichen Planus," Indian Journal of Dental Research, vol. 20, no. 3, pp. 288-292, 2009.

[249] M. Soto Araya, G. Rojas Alcayaga, and A. Esguep, "Association between psychological disorders and the presence of Oral Lichen Planus, Burning mouth syndrome and Recurrent aphthous Stomatitis," Medicina Oral, vol. 9, no. 1, pp. 1-7, 2004.

[250] X. H. Wu, X. D. He, S. H. Wu, and H. Xia, "Study of association between oral Lichen Planus and depression in female patients," Shanghai Kou Qiang Yi Xue, vol. 20, no. 5, pp. 548-552, 2011.

[251] R. I. Macleod, "Psychological factors in oral Lichen Planus," British Dental Journal, vol. 173, no. 3, p. 88, 1992.

[252] A. Akay, A. Pekcanlar, K. E. Bozdag, L. Altintas, and A. Karaman, "Assessment of depression in subjects with psoriasis vulgaris and Lichen Planus," Journal of the European Academy of Dermatology and Venereology, vol. 16, no. 4, pp. 347-352, 2002.

[253] F. Chiappelli, M. A. Kung, P. Nguyen, P. Villanueva, E. Arash Farhadian, and L. R. Eversole, "Cellular immune correlates of clinical severity in oral Lichen Planus: preliminary association with mood states," Oral Diseases, vol. 3, no. 2, pp. 64-70, 1997.

[254] K. Ivanovski, M. Nakova, G. Warburton et al., "Psychological profile in oral Lichen Planus," Journal of Clinical Periodontology, vol. 32, no. 10, pp. 1034-1040, 2005.

[255] Z. Puchalski, "Psychosomatic aspects in patients with alopecia areata, rosacea and lichen ruber planus," Zeitschrift fur Hautkrankheiten, vol. 58, no. 22, pp. 1648-1654, 1983. 
[256] D. De and A. Kanwar, "Eruptive Lichen Planus in a child with celiac disease," Indian Journal of Dermatology, Venereology and Leprology, vol. 74, no. 2, pp. 164-165, 2008.

[257] F. Fortune and J. A. G. Buchanan, "Oral Lichen Planus and coeliac disease," The Lancet, vol. 341, no. 8853, pp. 1154-1155, 1993.

[258] C. Scully, S. R. Porter, and J. W. Eveson, "Oral Lichen Planus and coeliac disease," The Lancet, vol. 341, no. 8861, p. 1660, 1993.

[259] D. Compilato, A. Carroccio, and G. Campisi, "Hidden coeliac disease in patients suffering from oral Lichen Planus," Journal of the European Academy of Dermatology and Venereology, vol. 26, no. 3, pp. 390-391, 2012.

[260] J. Ikeda, T. Kohriyama, H. Maruyama, T. Tanaka, and S. Nakamura, "A patient of myasthenia gravis complicated by Lichen Planus 9 years after thymectomy," Clinical Neurology, vol. 39, no. 6, pp. 625-628, 1999.

[261] T. C. Mineo, F. Biancari, and V. D’Andrea, "Myasthenia gravis, psychiatric disturbances, idiopathic thrombocytopenic purpura, and Lichen Planus associated with cervical thymoma," Journal of Thoracic and Cardiovascular Surgery, vol. 111, no. 2, pp. 486-487, 1996.

[262] G. Ghigliotti, A. Nigro, C. Gambini, A. Burroni, and R. De Marchi, "Lichen Planus and thymoma. A case report," Annales de Dermatologie et de Venereologie, vol. 122, no. 10, pp. 692-694, 1995.

[263] I. K. Aronson, K. Soltani, K. I. Paik, D. Rubenstein, and A. L. Lorincz, "Triad of Lichen Planus, myasthenia gravis, and thymoma," Archives of Dermatology, vol. 114, no. 2, pp. 255-258, 1978.

[264] T. N. Miller, "Myasthenia gravis, ulcerative colitis and Lichen Planus," Proceedings of the Royal Society of Medicine, vol. 64, no. 8, pp. 807-808, 1971.

[265] J. Qiao, G. Zhou, Y. Ding, D. Zhu, and H. Fang, "Multiple paraneoplastic syndromes: myasthenia gravis, vitiligo, alopecia areata, and oral Lichen Planus associated with thymoma," Journal of the Neurological Sciences, vol. 308, no. 1-2, pp. 177-179, 2011.

[266] M. Blanchard, A. Méneret, P. Moguelet et al., "Oral erosive Lichen Planus associated with Good syndrome," Revue de Medecine Interne, vol. 31, no. 7, pp. 498-501, 2010.

[267] H. S. Inalöz, M. M. U. Chowdhury, and R. J. Motley, "Lupus erythematosus/Lichen Planus overlap syndrome with scarring alopecia," Journal of the European Academy of Dermatology and Venereology, vol. 15, no. 2, pp. 171-174, 2001.

[268] H. Kim and M. K. Pomeranz, "Lupus erythematosus and Lichen Planus overlap syndrome," Journal of Drugs in Dermatology, vol. 3, no. 3, pp. 311-312, 2004.

[269] K. Nagao and K. Chen, "A case of lupus erythematosus/Lichen Planus overlap syndrome," Journal of Dermatology, vol. 33, no. 3, pp. 187-190, 2006.

[270] T. Kobayashi, A. Hatamochi, N. Kamada, H. Matsue, and H. Shinkai, "Systemic lupus erythematosus with Lichen Planuslike eruptions associated with pericarditis," Journal of Dermatology, vol. 35, no. 5, pp. 306-307, 2008.

[271] A. Bermejo Fenoll and M. P. López Jornet, "Oral Lichen Planus and Sjogren's syndrome. 2 cases of association," Avances en Odontoestomatologia, vol. 7, no. 1, pp. 29-38, 1991.

[272] H. Tsuboi and K. Katsuoka, "Ulcerative Lichen Planus associated with Sjögren's syndrome," Journal of Dermatology, vol. 34, no. 2, pp. 131-134, 2007.
[273] J. Sepčić, R. Ristić, O. Perković et al., "A case of lichen ruber planus in a patient with familial multiple sclerosis," Journal of International Medical Research, vol. 38, no. 5, pp. 1856-1860, 2010.

[274] M. Siponen, L. Huuskonen, E. Läärä, and T. Salo, "Association of oral Lichen Planus with thyroid disease in a Finnish population: a retrospective case-control study," Oral Surgery, Oral Medicine, Oral Pathology, Oral Radiology and Endodontology, vol. 110, no. 3, pp. 319-324, 2010.

[275] C. Fite, F. Plantier, N. Dupin, M. Avril, and M. Moyal-Barracco, "Vulvar verruciform xanthoma: ten cases associated with lichen sclerosus, Lichen Planus, or other conditions," Archives of Dermatology, vol. 147, no. 9, pp. 1087-1092, 2011.

[276] M. K. A. Basra, R. Fenech, R. M. Gatt, M. S. Salek, and A. Y. Finlay, "The dermatology life quality index 1994-2007: a comprehensive review of validation data and clinical results," British Journal of Dermatology, vol. 159, no. 5, pp. 997-1035, 2008.

[277] D. D. Balci and T. Inandi, "Dermatology life quality index scores in Lichen Planus: comparison of psoriasis and healthy controls," Turkderm Deri Hastaliklari ve Frengi Arsivi, vol. 42, no. 4, pp. 127-130, 2008.

[278] G. D. Slade and A. J. Spencer, "Development and evaluation of the oral health impact profile," Community Dental Health, vol. 11, no. 1, pp. 3-11, 1994.

[279] P. López-Jornet and F. Camacho-Alonso, "Quality of life in patients with oral Lichen Planus," Journal of Evaluation in Clinical Practice, vol. 16, no. 1, pp. 111-113, 2010.

[280] P. López-Jornet, F. Camacho-Alonso, and M. Lucero Berdugo, "Measuring the impact of oral mucosa disease on quality of life," European Journal of Dermatology, vol. 19, no. 6, pp. 603-606, 2009.

[281] A. M. Hegarty, C. McGrath, T. A. Hodgson, and S. R. Porter, "Patient-centred outcome measures in oral medicine: are they valid and reliable?" International Journal of Oral and Maxillofacial Surgery, vol. 31, no. 6, pp. 670-674, 2002.

[282] B. T. Accurso, B. M. Warner, T. J. Knobloch et al., "Allelic imbalance in oral Lichen Planus and assessment of its classification as a premalignant condition," Oral Surgery, Oral Medicine, Oral Pathology, Oral Radiology and Endodontology, vol. 112, no. 3, pp. 359-366, 2011.

[283] M. Vered, E. Fürth, Y. Shalev, and D. Dayan, "Inflammatory cells of immunosuppressive phenotypes in oral Lichen Planus have a proinflammatory pattern of expression and are associated with clinical parameters," Clinical Oral Investigations, vol. 17, no. 5, pp. 1365-1373, 2013.

[284] P. Shi, W. Liu, Z. Zhou, Q. He, and W. Jiang, "Podoplanin and ABCG2: malignant transformation risk markers for oral Lichen Planus," Cancer Epidemiology Biomarkers and Prevention, vol. 19, no. 3, pp. 844-849, 2010.

[285] S. Silverman Jr., M. Gorsky, and F. Lozada-Nur, "A prospective follow-up study of 570 patients with oral Lichen Planus: persistence, remission, and malignant association," Oral Surgery Oral Medicine and Oral Pathology, vol. 60, no. 1, pp. 30-34, 1985.

[286] M. Honma, M. Minami-Hori, H. Takahashi, and H. Iizuka, "Podoplanin expression in wound and hyperproliferative psoriatic epidermis: regulation by TGF- $\beta$ and STAT- 3 activating cytokines, IFN- $\gamma$, IL-6, and IL-22," Journal of Dermatological Science, vol. 65, no. 2, pp. 134-140, 2012. 
[287] A. Gandarillas, F. G. Scholl, N. Benito, C. Gamallo, and M. Quintanilla, "Induction of PA2. 26, a cell-surface antigen expressed by active fibroblasts, in mouse epidermal keratinocytes during carcinogenesis," Molecular Carcinogenesis, vol. 20, no. 1, pp. 10-18, 1997.

[288] Y. Higashikuni, J. Sainz, K. Nakamura et al., “The ATP-binding cassette transporter BCRP1/ABCG2 plays a pivotal role in cardiac repair after myocardial infarction via modulation of microvascular endothelial cell survival and function," Arteriosclerosis, Thrombosis, and Vascular Biology, vol. 30, no. 11, pp. 2128-2135, 2010.

[289] Z. Marcekova, M. J. Flaig, M. Kekus, T. Ruzicka, and R. A. Rupec, "The potential role of c-Jun activation in patients with cutaneous Lichen Planus," Experimental Dermatology, vol. 19, no. 1, pp. 74-80, 2010.

[290] E. Eisenberg, "Oral Lichen Planus: a benign lesion," Journal of Oral and Maxillofacial Surgery, vol. 58, no. 11, pp. 1278-1285, 2000.

[291] G. P. Bombeccari, G. Guzzi, M. Tettamanti et al., "Oral Lichen Planus and malignant transformation: a longitudinal cohort study," Oral Surgery, Oral Medicine, Oral Pathology, Oral Radiology and Endodontology, vol. 112, no. 3, pp. 328-334, 2011.

[292] L. Lo Muzio, M. D. Mignogna, G. Favia, M. Procaccini, N. F. Testa, and E. Bucci, "The possible association between oral Lichen Planus and oral squamous cell carcinoma: a clinical evaluation on 14 cases and a review of the literature," Oral Oncology, vol. 34, no. 4, pp. 239-246, 1998.

[293] F. Gorouhi, A. Solhpour, J. M. Beitollahi et al., "Randomized trial of pimecrolimus cream versus triamcinolone acetonide paste in the treatment of oral Lichen Planus," Journal of the American Academy of Dermatology, vol. 57, no. 5, pp. 806-813, 2007.

[294] A. B. E. Voute, W. F. B. De Jong, E. A. J. M. Schulten, G. B. Snow, and I. Van Der Waal, "Possible premalignant character of oral Lichen Planus. The Amsterdam experience," Journal of Oral Pathology and Medicine, vol. 21, no. 7, pp. 326-329, 1992.

[295] R. S. Brown, W. K. Bottomley, E. Puente, and G. J. Lavigne, "A retrospective evaluation of 193 patients with oral Lichen Planus," Journal of Oral Pathology and Medicine, vol. 22, no. 2, pp. 69-72, 1993.

[296] T. Zheng, P. Boyle, H. Hu et al., "Dentition, oral hygiene, and risk of oral cancer: a case-control study in Beijing, People's Republic of China," Cancer Causes and Control, vol. 1, no. 3, pp. 235-241, 1990. 


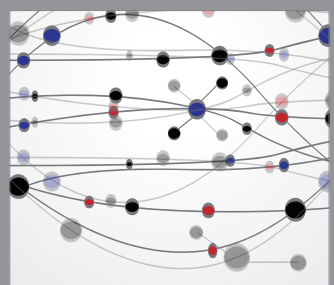

The Scientific World Journal
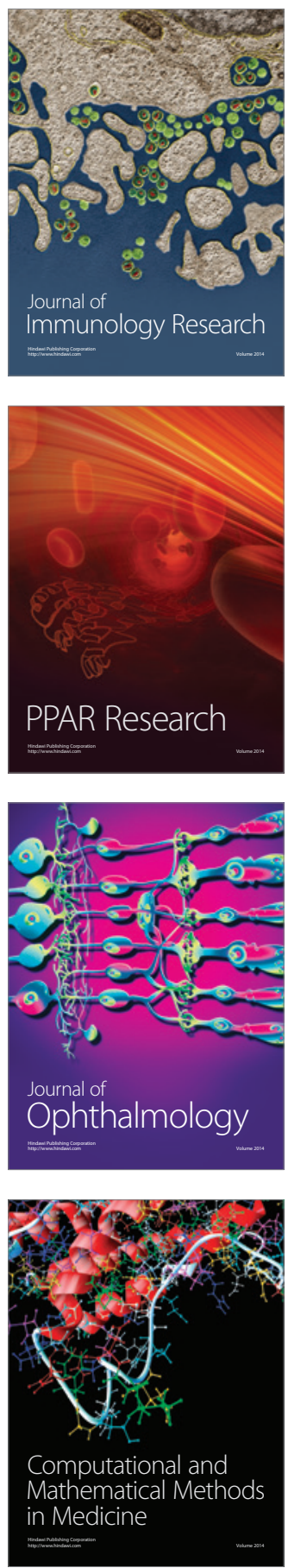

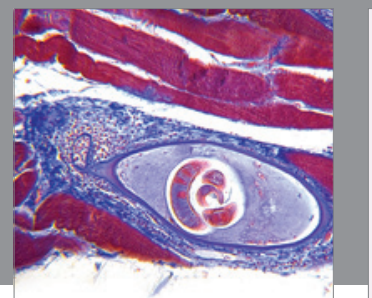

Gastroenterology

Research and Practice
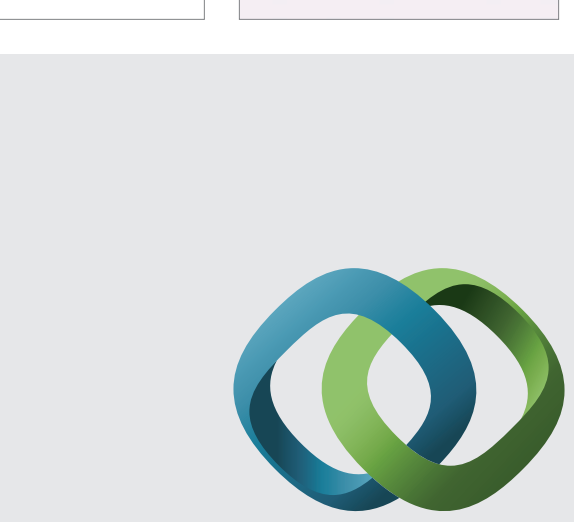

\section{Hindawi}

Submit your manuscripts at

http://www.hindawi.com
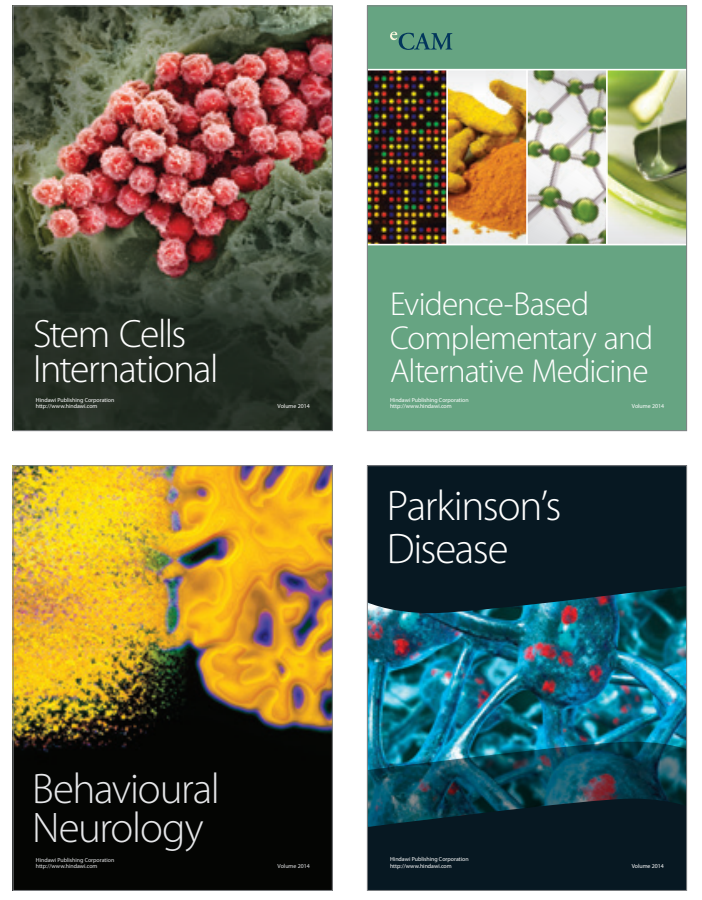
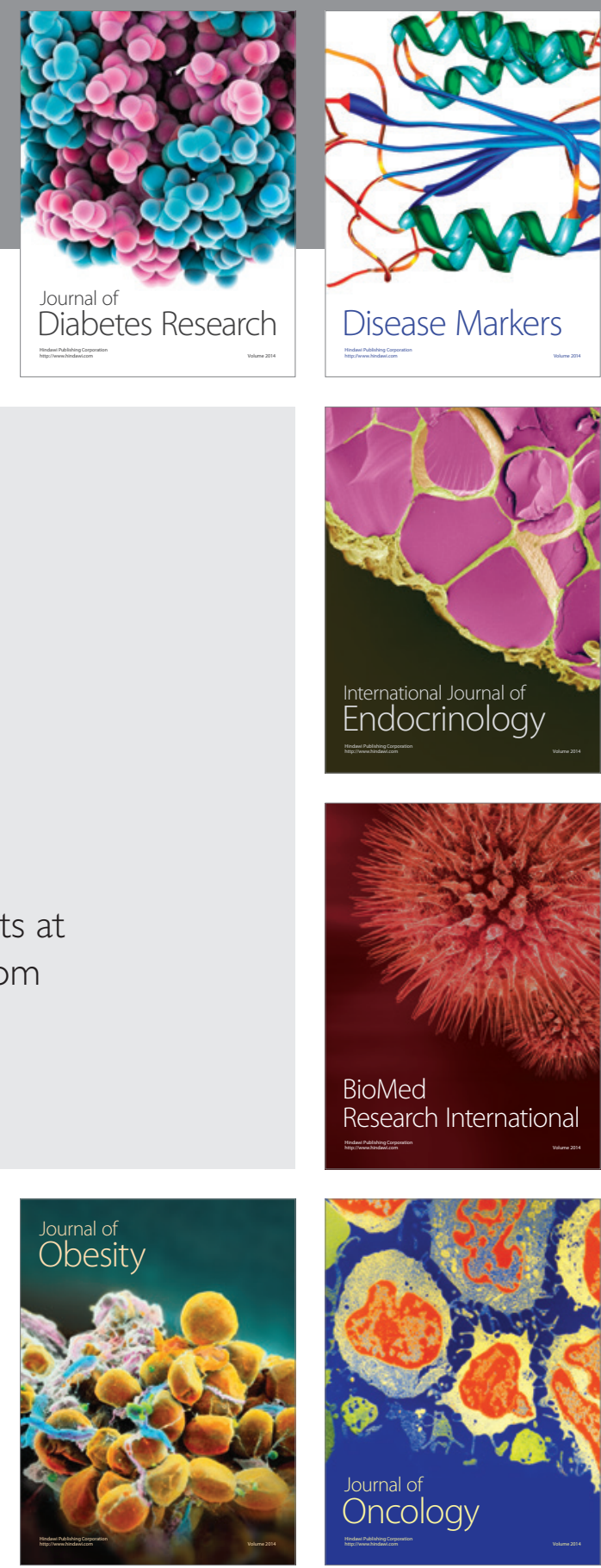

Disease Markers
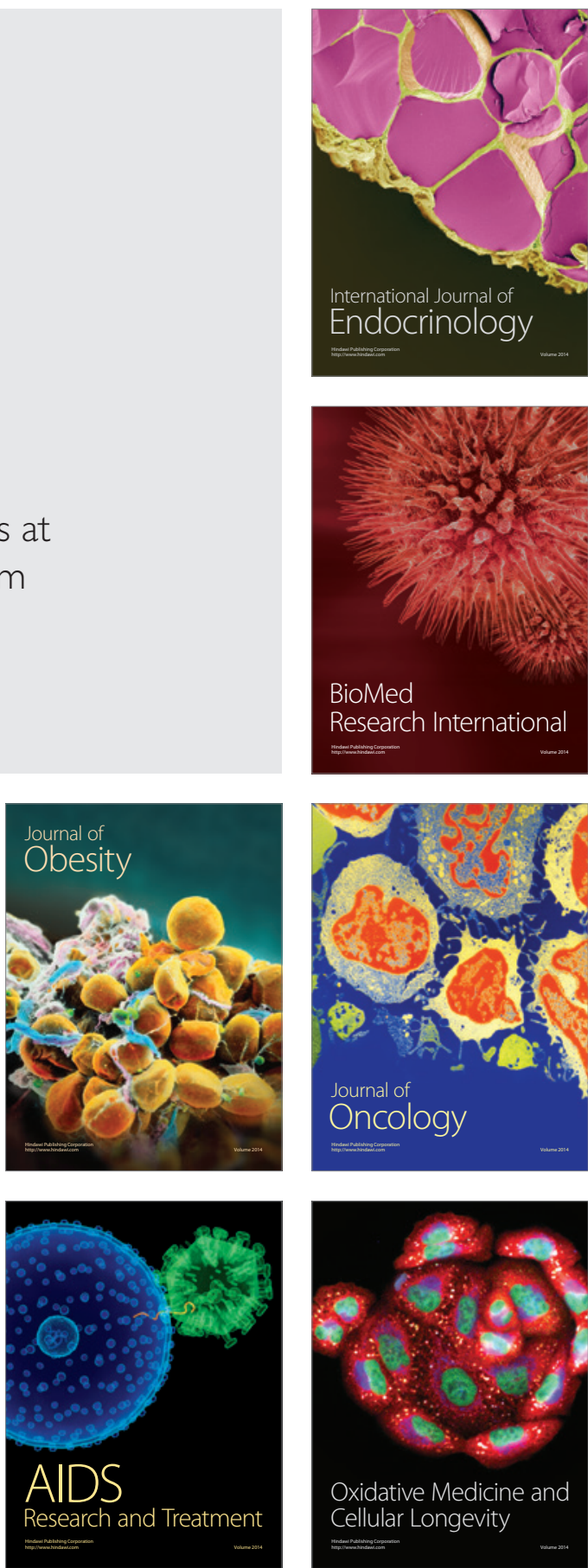